OPEN ACCESS

Edited by:

Andres Trostchansky,

University of the Republic, Uruguay

Reviewed by:

Bruno Araujo Serra Pinto,

Federal University of Maranhão, Brazil

Vittorio Calabrese,

University of Catania, Italy

*Correspondence:

Xinmin Liu

liuxinmin@hotmail.com

Qiong Wang

luyiwangqiong@163.com; qimplad@126.com

Specialty section: This article was submitted to Experimental Pharmacology

and Drug Discovery,

a section of the journal

Frontiers in Pharmacology

Received: 21 February 2020

Accepted: 20 May 2020

Published: 10 June 2020

Citation:

Yang Y, Li S, Huang H, LV J, Chen S, Pires Dias A, Li Y, Liu X and Wang Q (2020) Comparison of the Protective

Effects of Ginsenosides Rb1

and Rg1 on Improving Cognitive

Deficits in SAMP8 Mice Based on Anti-Neuroinflammation Mechanism.

Front. Pharmacol. 11:834.

doi: 10.3389/fphar.2020.00834

\title{
Comparison of the Protective Effects of Ginsenosides Rb1 and Rg1 on Improving Cognitive Deficits in SAMP8 Mice Based on Anti- Neuroinflammation Mechanism
}

Yujie Yang ${ }^{1}$, Shanshan $L i^{1}$, Hong Huang ${ }^{2}$, Jingwei $L v^{2}$, Shanguang Chen ${ }^{3}$, Alberto Carlos Pires Dias ${ }^{4}$, Yujiao $\mathrm{Li}^{1}$, Xinmin $\mathrm{Liu}^{1,2 *}$ and Qiong Wang ${ }^{1,3,5 *}$

${ }^{1}$ Affiliated TCM Hospital, School of Pharmacy, Sino-Portugal TCM International Cooperation Center, Southwest Medical University, Luzhou, China, ${ }^{2}$ Research Center for Pharmacology \& Toxicology, Institute of Medicinal Plant Development (IMPLAD), Chinese Academy of Medical Sciences and Peking Union Medical College, Beijing, China, ${ }^{3}$ Institute of Food Science and Technology, Chinese Academy of Agricultural Sciences (CAAS), Beijing, China, ${ }^{4}$ Centre of Molecular and Environmental Biology (CBMA), SINO-PT Research Center, Department of Biology, University of Minho, Braga, Portugal, ${ }^{5}$ National Key Laboratory of Human Factors Engineering, China Astronaut Research and Training Center, Beijing, China

This present study was designed to investigate the different effects of ginsenosides Rb1 and Rg1 on improving cognitive deficits in 4-month-old SAMP8 mice. Mice were divided into six groups, including the SAMP8 group, the SAMP8 + Donepezil $(1.6 \mathrm{mg} / \mathrm{kg}) \mathrm{group}$, the SAMP8 + Rb1 (30 and $60 \mu \mathrm{mol} / \mathrm{kg}$ ), and SAMP8 + Rg1 (30 and $60 \mu \mathrm{mol} / \mathrm{kg}$ ) groups. SAMR1 mice of the same age were used as the control group. Ginsenosides and donepezil were administrated orally to animals for 8 weeks, then the learning and memory ability of mice were measured by using Morris water maze (MWM) test, object recognition test and passive avoidance experiments. The possible mechanisms were studied including the anti-glial inflammation of Rb1 and Rg1 using HE staining, immunohistochemistry and western blot experiments. Results revealed that Rb1 and Rg1 treatment significantly improved the discrimination index of SAMP8 mice in the object recognition test. $\mathrm{Rb} 1(60 \mu \mathrm{mol} / \mathrm{kg})$ and $\mathrm{Rg} 1(30,60 \mu \mathrm{mol} / \mathrm{kg})$ could significantly shorten the escape latency in the acquisition test of the MWM test in SAMP8 mice. Furthermore, $\mathrm{Rb} 1$ and Rg1 treatments effectively reduced the number of errors in the passive avoidance task in SAMP8 mice. Western blot experiments revealed that Rb1 showed higher effect than $\mathrm{Rg} 1$ in decreasing protein expression levels of $A S C$, caspase-1 and $A \beta$ in the hippocampus of SAMP8 mice, while Rg1 was more effective than Rb1 in decreasing the protein levels of iNOS. In addition, although Rb1 and Rg1 treatments showed significant protective effects in repairing neuronal cells loss and inhibiting the activation of astrocyte and microglia in hippocampus of SAMP8 mice, Rb1 was more effective than Rg1. These results suggest that $\mathrm{Rb} 1$ and $\mathrm{Rg} 1$ could improve the cognitive impairment in SAMP8 mice, and they have different mechanisms for the treatment of Alzheimer's disease. 


\section{INTRODUCTION}

Alzheimer's disease (AD) is a neurodegenerative disease with complex pathogenic factors. Its main symptoms are cognitive impairment, execution disorder, memory impairment, obvious mental disorder, sleep disorder, and even behavioral abnormalities (Yang et al., 2017; Yutaro et al., 2018). Many studies have indicated the cardinal features of Alzheimer pathology are amyloid plaques, neurofibrillary tangles (NFTs), associated with astrogliosis and microglial activation (Lane et al., 2018; Boumenir et al., 2019). In recent years, increasing evidence suggests that neuroinflammation is a causal role in the pathogenesis of AD (Heneka et al., 2015; Zhang et al., 2015). Apoptotic process closely associated with inflammasome, and lead to neuronal cell death in AD (Xingxing and Tao, 2018). Microglia and astrocyte are the main cells involved in neuroinflammatory reactions. Activated microglia and astrocyte can produce pro-inflammatory cytokines such as tumor necrosis factor- $\alpha$ (TNF- $\alpha$ ), interleukin- $1 \beta$ (IL-1 $\beta$ ), and interleukin-6 (IL-6) (Kima et al., 2019).

Ginsenosides are the main active components of Panax ginseng C. A. Meyer, a traditional chinese herbal medicine, which has a wide range of pharmacological effects, such as anti-aging, anti-tumor, and nervous system protection, etc. In recent years, researches have indicated that ginsenosides play a pronounced positive role in the treatment of AD (Razgonova et al., 2019) and have memory enhancement effects (Wang et al., 2016). Ginsenosides Rg1 and Rb1 are the major ginsenosides in ginseng with identified neuroprotective effects. Rg1 can decreased $A \beta$ level, attenuated hippocampal histopathological abnormalities and improved learning and memory in a rat model of $\mathrm{AD}$ induced by injection of soluble beta-amyloid peptide 1-42 $\left(\mathrm{Ab}_{1-42}\right)$ into the hippocampus (Quan et al., 2013). Rb1 reversed memory impairment induced by aluminum (Al)-exposure, probably through preventing tau hyperphosphorylation by regulating p-GSK3 and PP2A level in the cortex and hippocampus (Zhao et al., 2013). Our previous studies have demonstrated that $\mathrm{Rg} 1$ and $\mathrm{Rb} 1$ intraperitoneal administration to mice for 7 days were both effective in improving memory deficiency induced by scopolamine, and Rg1 was more effective than $\mathrm{Rb} 1$ in improving acquisition deficiency in the MWM test. In addition, Rg1 can significantly reduce AChE activity than Rb1, while $\mathrm{Rb} 1$ showed stronger effects than Rg1 in adjusting 5-HT level in hippocampus in mice (Wang et al., 2010). These results demonstrated that $\mathrm{Rb} 1$ and $\mathrm{Rg} 1$ have different neuroprotective mechanisms. So in this study, we assessed the cognitive enhancement effects of Rg1 and Rb1 in SAMP8 (senescence accelerated mice P8) mice to make better understand of their differences.

\section{MATERIALS AND METHODS}

\section{Animals}

Sixty-six male SAMP8 mice (4-month-old) and 12 male SAMR1 mice (4-month-old) were purchased from the
Department of Experimental Animal Science, Peking University Health Science Center (Qualified No. SCXK 2016-0010, Beijing, China). All animals were kept under a controlled environment of 12-h light/dark (8:30 AM-8:30 $\mathrm{PM})$ cycle at $23-25^{\circ} \mathrm{C}$ and a relative humidity of $50 \% \pm 10 \%$. They had free access to food and water throughout the experiment. All experimental procedures were performed under the approval and supervision of the Care and Use of Laboratory Animals of IMPLAD, CAMS \& PUMC, China (SLXD-20181225051), and in accordance with the National Institute of Health Guide for the Care and Use of Laboratory Animals. And all efforts were made to minimize the suffering of the animals.

\section{Chemicals and Reagents}

Ginsenoside Rg1 and ginsenoside Rb1 (purity > 98\%) were purchased from Ruifensi Biological Technology Co., Ltd. (Chengdu, China). Donepezil hydrochloride was purchased from Eisai pharmaceutical Co., Ltd (Shanghai, China).

\section{Experimental Design and Treatment}

One month after breeding, SAMP8 mice were randomly assigned to six groups as introduced in the abstract. The mice in SAMP8 + $\mathrm{Rb} 1, \mathrm{Rg} 1$, or donepezil group were treated daily correspongding drugs for 8 consecutive weeks before behavioral tests. The mice in SAMR1 control group and the SAMP8 model group received orally purified water during the experiment. Rb1, Rg1, and donepezil were prepared with purified water and were administered orally to mice at $0.1 \mathrm{ml} / 10 \mathrm{~g}$ per day (Figure $\mathbf{1}$ ).

All behavioral experiments were conducted after $1 \mathrm{~h}$ of drug administration.

\section{Behavioral Experiments \\ Object Location Recognition (OLR) Test}

The OLR test was used to evaluate the short-term and spatial object recognition memory of mice (Ennaceur et al., 2009). The procedure was divided into three stages: habituation, familiarization, and test phases. In the habituation phase, mice were allowed to explore the box (with no objects) for 10 min to acclimatize to the apparatus and reduce the animals' fear of a new environment. The habituation phase was repeated for three consecutive days. On the fourth day, the familiarization and test phases bagan. Firstly, two identical objects were fixed at the adjacent magnets in the chamber, and mice were allowed to freely explore the box for $5 \mathrm{~min}$. Then, after an interval of $30 \mathrm{~min}$, mice were returned to the box in which one of the original objects changed location ("novel") and the other object remained in the original position ("familiar"), and mice were allowed to freely explore the box for 5 min again. Recognition memory was evaluated by the following formula: $\mathrm{DI}=(\mathrm{TN}-\mathrm{TF}) /(\mathrm{TN}+\mathrm{TF})$. $\mathrm{DI}$ (discrimination index) refers to the difference between the time exploring the novel and the familiar object, corrected for total time exploring both objects. TN refers to the time spent exploring the "novel" object, and TF refers to the time spent exploring the "familiar" object (Lu et al., 2018a). 


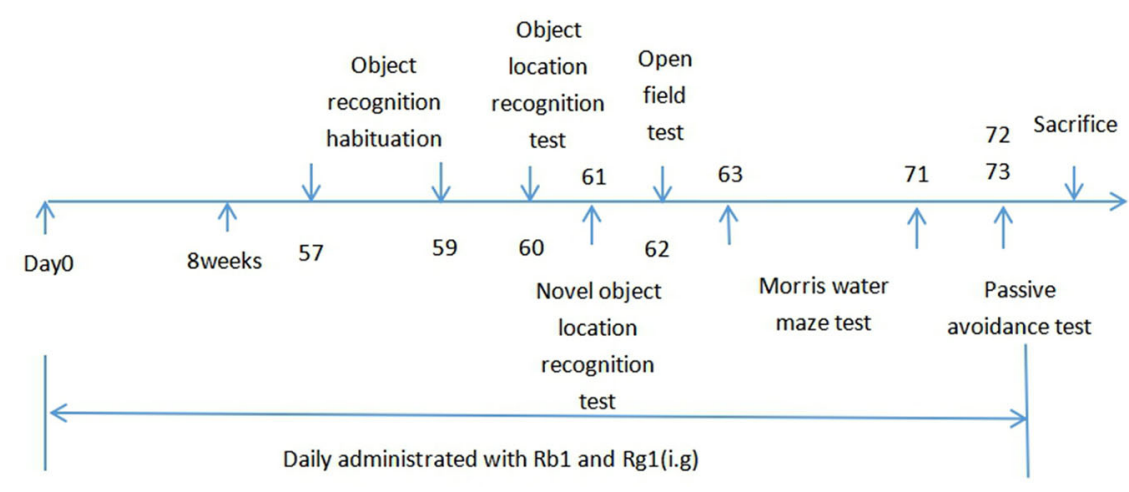

FIGURE 1 | Timeline for the experimental procedure.

\section{Novel Object Recognition (NOR) Test}

Twenty-four hours after the OLR test, the NOR test was carried out, including the familiarization phase and the test phase, with an interval of $30 \mathrm{~min}$ between two phases. The familiarization phase performed similarly to the OLR test. In the test phase, mice were returned to the box in which one of the original objects was replaced by a new one ("novel") and the other object remained ("familiar"), and mice were allowed to freely explore the box for 5 min. Recognition memory was evaluated by the following formula: $\mathrm{DI}=(\mathrm{TN}-\mathrm{TF}) /(\mathrm{TN}+\mathrm{TF})$ corresponding to the difference between the time exploring the novel and the familiar object, corrected for total time exploring both objects ( $\mathrm{TN}=$ time spent exploring the "novel" object; $\mathrm{TF}=$ time spent exploring the "familiar" object) (Lu et al., 2018b).

\section{Open Field Test}

The open field test used to assess the effects of Rb1 and Rg1 on the locomotor activity for eliminating its interference in cognitive function. The apparatus contain four identical boxes $(30 \mathrm{~cm} \times 28 \mathrm{~cm} \times 35 \mathrm{~cm})$. After $30 \mathrm{~min}$ of drug administration, each mouse was placed into the center of the box and allowed to explore freely for $3 \mathrm{~min}$. We recorded the total distances and average speeding of the mice in $10 \mathrm{~min}$. The floor of the box was cleaned with $70 \%$ ethanol after each trial.

\section{Morris Water Maze (MWM) Test}

The water maze was consisted of a circular, black pool measuring $100 \mathrm{~cm}$ in diameter and $38 \mathrm{~cm}$ in height, filled with opaque water (black ink) at the temperature of $23 \pm 1^{\circ} \mathrm{C}$, with a depth of $25 \mathrm{~cm}$. A submerged ( $1.5 \mathrm{~cm}$ beneath water surface) platform was fixed in the pool (the target quadrant). Objects and staff were fixed as the spatial reference to the mice during the experiment (Yang et al., 2018). The MWM test composed of three sections including the acquisition, the probe trail, and the reverse memory tests.

\section{Acquisition Phase (Learning)}

In the acquisition test, mice were trained three times daily during 6 consecutive days. Before each train, mice were placed on the hidden platform for $15 \mathrm{~s}$ to remember the location of platform. Then, they were put in the pool and allowed to find the platform for $90 \mathrm{~s}$. If mice succeed to find the platform and stay on it for $2 \mathrm{~s}$, it was considered as a successful platform search. If the mice failed to locate the hidden platform within $90 \mathrm{~s}$, the mice were gently guided to the platform, and allowed to stay there for $15 \mathrm{~s}$. The escape latency, the swimming distance, and average speed were recorded every day during the test.

\section{Probe Trial (Memory Consolidation)}

Twenty-four hours after the acquisition test, the probe trail was conducted to assess spatial reference memory of the animals, in which the platform was removed. The mice were released from the opposite quadrant of target quadrant. The numbers of target crossing of mice within $90 \mathrm{~s}$ were recorded to reflect the retention memory for the platform location.

\section{Reverse Test (Reverse Memory)}

In this section, the platform was moved to the opposite side of the target quadrant to assess the animals' reverse memory (Jinfeng et al., 2013). The process of this test was similar to the acquisition test. The mice were allowed to find the hidden platform in $90 \mathrm{~s}$, and the escape latency to find the platform was recorded. The test was last for 2 days.

\section{Passive Avoidance Test}

The step-through passive avoidance test box includes a dark chamber and a light chamber with stainless steel grids. The mice encountered an acquisition trail and a consolidation trail. In the acquisition trial, after $3 \mathrm{~min}$ habitation, each mouse was put into the test box from the light chamber and allowed to explore $5 \mathrm{~min}$ in the test box. When the mouse entered the dark chamber, it will suffer to $0.5 \mathrm{~mA}$ electric foot shock in dark chamber. Twentyfour hours later, the consolidation trial was performed as before. The latency and the error times to enter the dark chamber were recorded in mice. This passive avoidance test was used to assess the non-spatial memory in mice. 


\section{Brain Sample Preparation}

After all behavioral tests, mice were anesthetized and sacrificed. The cortical and hippocampal regions were collected and deep frozen in liquid nitrogen followed by transfer to $-80^{\circ} \mathrm{C}$ for further analysis.

\section{Brain Immunohistochemistry}

Three mice of each group were anesthetized with 5\% chloral hydrate and transcardially perfused with $0.9 \%$ saline followed by $4 \%$ paraformaldehyde. Brains were removed and post-fixed in the same fixative solution for $24 \mathrm{~h}$ at $4^{\circ} \mathrm{C}$. All immunohistochemistry procedures were conducted according to the previously studies (Aragão et al., 2018; Lamarão-Vieira et al., 2019). Paraffinembedded sections were dewaxed, hydrated, and rinsed. Then, antigen recovery was performed with citrate buffer solution $(\mathrm{pH}$ 6.0), previously heated to $60^{\circ} \mathrm{C}$ for $23 \mathrm{~min}$. Sections were kept at room temperature for $20 \mathrm{~min}$ to decrease the temperature and incubated in $3 \%$ hydrogen peroxide solution $\left(\mathrm{H}_{2} \mathrm{O}_{2}\right)$ for $25 \mathrm{~min}$ to block endogenous peroxidase and then incubated with antibodies. After that, sections were incubated with 3\% bovine serum albumin (BSA, Solarbio) for $30 \mathrm{~min}$. Primary antibodies were against Iba-1 (Abcam, Ab178847) and GFAP (CST, 12389s). Sections were rinsed three times ( $5 \mathrm{~min} /$ time) with $0.1 \mathrm{M}$ phosphate-buffered saline (PBS, $\mathrm{PH}$ 7.4) and revealed with 3, 3-diaminobenzidine (DAB). After DAB staining, sections were counterstained by hematoxylin for $3 \mathrm{~min}$, dehydrate through alcohol gradient and xylene. The sections observed under microscope and the activated cells counted from three different areas in each section.

\section{Statistical Analysis}

All data were analyzed using the SPSS 21.0 software package (IBM, USA) and represented as means \pm standard error of the mean (SEM). The data of the acquisition trials in MWM were analyzed using the two-way repeated measures ANOVA, and other data were analyzed by one-way ANOVA followed by multiple post hoc comparisons using the least significant difference (LSD) test. P value 0.05 was considered statistically significant difference.

\section{RESULTS}

\section{Effects of Ginsenosides Rb1 and Rg1 on the OLR Task in SAMP8 Mice}

In the familiarization phase, Figure $\mathbf{2 A}$ showed that compared to the SAMR1 mice, SAMP8 mice did not significant differences in the total exploration time $(p>0.05)$. Treatment with $\mathrm{Rb} 1(30,60$ $\mu \mathrm{mol} / \mathrm{kg}), \operatorname{Rg} 1(30,60 \mu \mathrm{mol} / \mathrm{kg})$ and donepezil did not showed significant changes in the total exploration time, which suggested that there were no differences on the ability of exploration and preference for location in mice. In the test phase, the DI of SAMP8 mice significantly decreased (32.79\%) compared with the SAMR1 mice, whereas all treatment groups elevated the DI significantly as compared to the SAMP8 group $(p<0.01$, Figure 2B), indicating both Rb1 and Rg1 administrations could improve the object location memory deficit in SAMP8 mice.

\section{Effects of Ginsenosides Rb1 and Rg1 on the NOR Task in SAMP8 Mice}

As shown in Figure 3A, in the familiarization phase, mice in the SAMR1, the SAMP8, the donepezil, the Rg1 and Rb1 treatment groups displayed non-significant similar preference toward two similar objects $(p>0.05)$. These results demonstrated that there was no significant difference on the ability of exploration and preference for object location in mice.

As indicated in Figure 3B, the DI of SAMP8 mice was $49.28 \%$ significantly lower than those in the SAMR1 group $(p<0.01)$. However, all treatment groups could significantly increase the DI in SAMP8 mice $(p<0.01)$. It illustrated that the SAMP8 mice treated with Rb1 or Rg1 could reverse the NOR memory deficit.

\section{Effects of Ginsenosides Rb1 and Rg1 on Locomotor Activity of SAMP8 Mice}

As shown in Figure 4, there was no significant difference between the SAMR1 and SAMP8 mice in the total distance $(p>0.05)$ and the average speed $(p>0.05)$. Treatment with $\mathrm{Rb} 1$, Rg1, or donepezil did not show significant difference in locomotor activity $(p>0.05)$. Results indicated that cognitive dysfunction did not affect locomotor activity in SAMP8 mice.
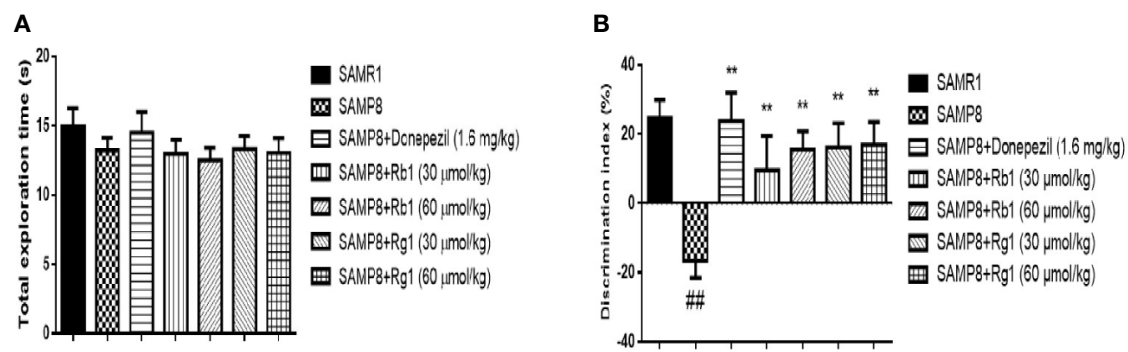

FIGURE 2 | Effects of ginsenosides Rb1 and Rg1 on short-term, spatial memory in object location recognition task. (A) Total exploration time in familiarization phase; (B) Discrimination index in test phase. All data were expressed as means \pm SEM $(n=10-12) .{ }^{\# \#} p<0.01$ versus the SAMR1 group; ${ }^{* *} p<0.01$ versus the SAMP8 group. 

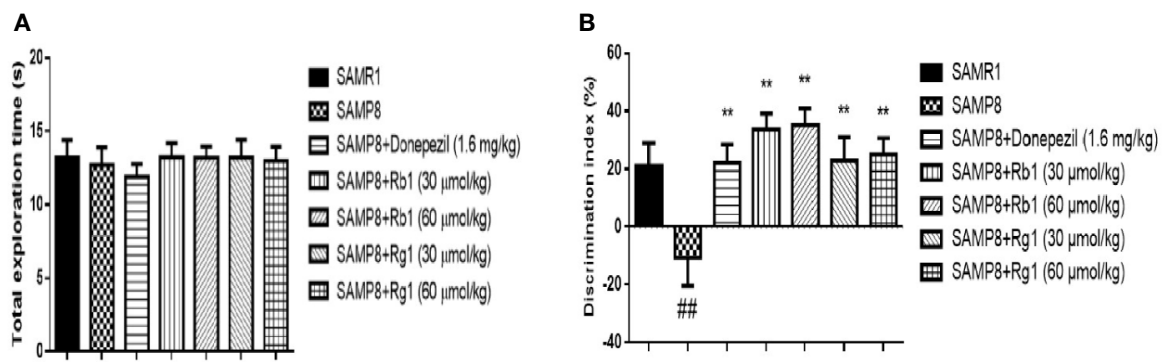

FIGURE 3 | Effects of ginsenosides Rb1 and Rg1 on short-term, non-spatial memory in novel object recognition task. (A) Total exploration time in familiarization phase; (B) Discrimination index in test phase. All data were expressed as means \pm SEM $(n=10-11)$. ${ }^{\# \#} p<0.01$ versus the SAMR1 group; ${ }^{* *} p<0.01$ versus the SAMP8 group.

\section{Effects of Ginsenosides Rb1 and Rg1 on Spatial Learning and Memory Deficits in the MWM Test in SAMP8 Mice}

In the acquisition test, as shown in Figures $\mathbf{5 A}, \mathbf{B}$, there was no significant difference in the average speed and total swimming distance in the SAMR1, SAMP8, donepezil, Rg1 and Rb1 groups from day 1 to day 6, except the average speed of the Rg1 $30 \mu \mathrm{mol} / \mathrm{kg}$ treatment group was higher than that of SAMP8 mice on day 2. In Figure 5C, the escape latency in the acquisition test in SAMP8 mice was significantly longer than that of the SAMR1 mice from day 5 (44.65\%) to day $6(41.20 \%)$, illustrating spatial reference memory impairment in SAMP8 mice $(p<0.05, p<0.01)$. Rb1 $(60 \mu \mathrm{mol} / \mathrm{kg})$ and $\operatorname{Rg} 1(30 \mu \mathrm{mol} / \mathrm{kg})$ treatment could significantly shorten the escape latency on day $6(p<0.05)$. In the probe trial (Figure 5D), the number of target crossings of SAMP8 mice was $42.85 \%$ lower than the SAMR1 mice $(p<0.05)$, while Rb1 or Rg1 treatment did not show significantly effect in SAMP8 mice.

As shown in Figure 6, the escape latency of SAMP8 mice was $45.79 \%$ longer than that of the SAMR1 mice on day 2, illustrating the ability of SAMP8 mice to relearn was affected $(p<0.05)$. Rg1 $(30 \mu \mathrm{mol} / \mathrm{kg})$ or donepezil treatment effectively decreased the escape latency on day 2 . These indicated that only Rg1 $(30 \mu \mathrm{mol} /$ $\mathrm{kg}$ ) could significantly improve the relearn ability dysfunction in SAMP8 mice.

\section{Effects of Ginsenosides Rb1 and Rg1 on Non-Spatial Memory Deficits in the Passive Avoidance Test}

In the acquisition phase, as shown in Figure 7A, the number of errors in SAMP8 mice was $57.52 \%$ higher than the SAMR1 mice $(p<0.05)$. The donepezil, $\mathrm{Rb} 1(30,60 \mu \mathrm{mol} / \mathrm{kg})$, or $\operatorname{Rg} 1(30,60$ $\mu \mathrm{mol} / \mathrm{kg}$ ) treatment could significantly reduce the number of errors in SAMP8 mice ( $p<0.05, p<0.01)$.

In the test phase (Figure 7B), the latency into the dark chamber of SAMP8 mice was $71.57 \%$ shorter than the SAMR1 mice $(p<0.01)$, while the donepezil, $\mathrm{Rb} 1$ (30 $\mu \mathrm{mol} / \mathrm{kg})$, or $\mathrm{Rg} 1$ $(60 \mu \mathrm{mol} / \mathrm{kg})$ treatment effectively extended the latency into the dark chamber in SAMP8 mice. Furthermore, the number of errors in SAMP8 group was more than twice of the SAMR1 mice $(p<0.05$, Figure 7C) and Rb1 $(30 \mu \mathrm{mol} / \mathrm{kg})$ treatment significantly decreased the number of errors in SAMP8 mice $(p<0.05)$.

\section{Effects of Ginsenosides Rb1 and Rg1 on TNF- $\alpha$ Levels in the Serum and the Cerebral Cortex of SAMP8 Mice}

As shown in Figure 8, the level of TNF- $\alpha$ in the serum of SAMP8 mice was $31.22 \%$ higher than of the SAMR1 mice $(p<0.05)$. Treatment with $\mathrm{Rb} 1(30,60 \mu \mathrm{mol} / \mathrm{kg})$ or donepezil significantly
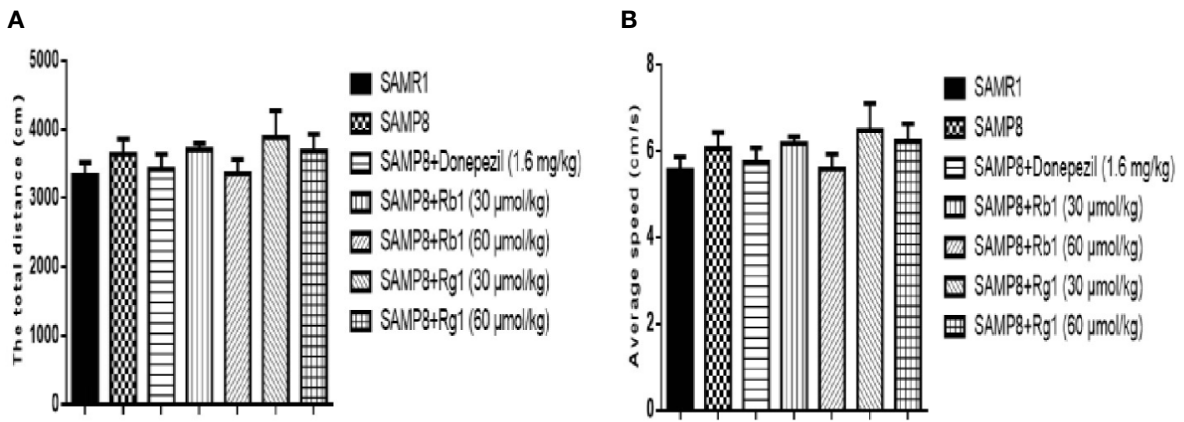

FIGURE 4 | Effects of ginsenosides Rb1 and Rg1 on the locomotor activities in SAMP8 mice. (A) The total distance. (B) Average speed. All data were expressed as means \pm SEM $(n=8-12)$. 

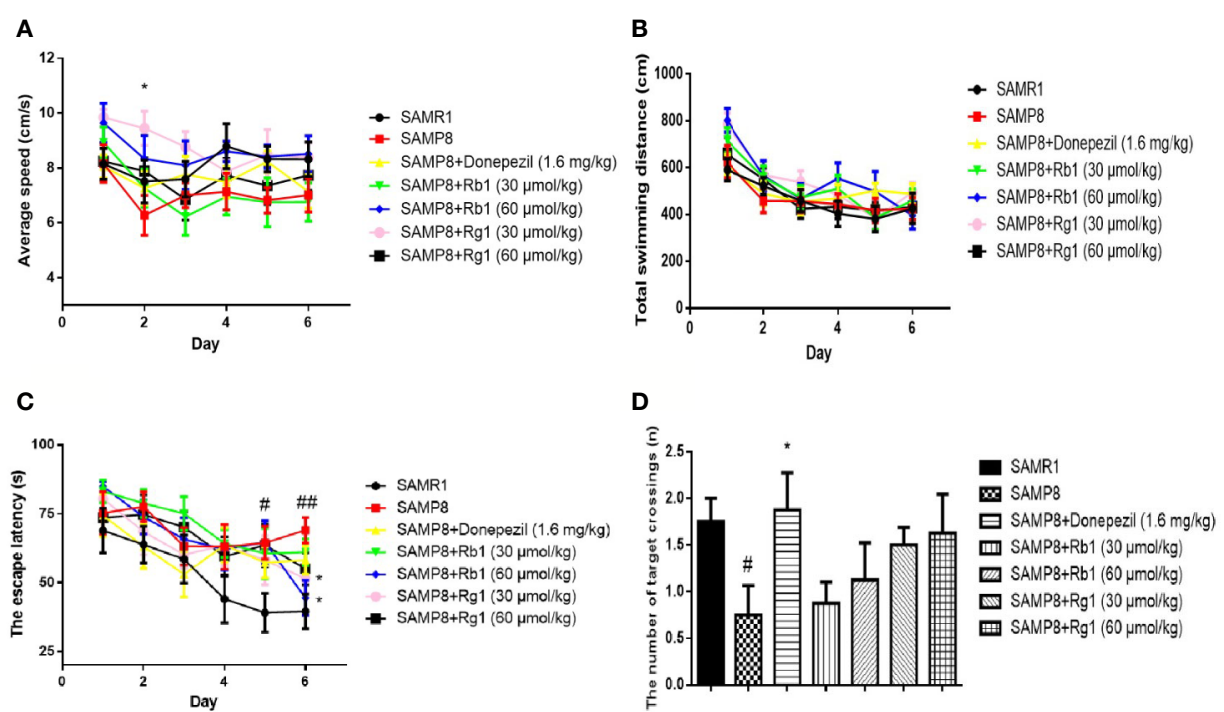

FIGURE 5 | Effects of ginsenosides Rb1 and Rg1 on the spatial learning and memory in the MWM test in SAMP8 mice. (A) Average speed. (B) Total swimming distance. (C) The escape latency. (D) The number of target crossings. All data were expressed as means \pm SEM ( $n=8-11)$. ${ }^{\#} p<0.05$, ${ }^{\# \#} p<0.01 v e r s u s$ the SAMR1 group; * $p<0.05$ versus the SAMP8 group.

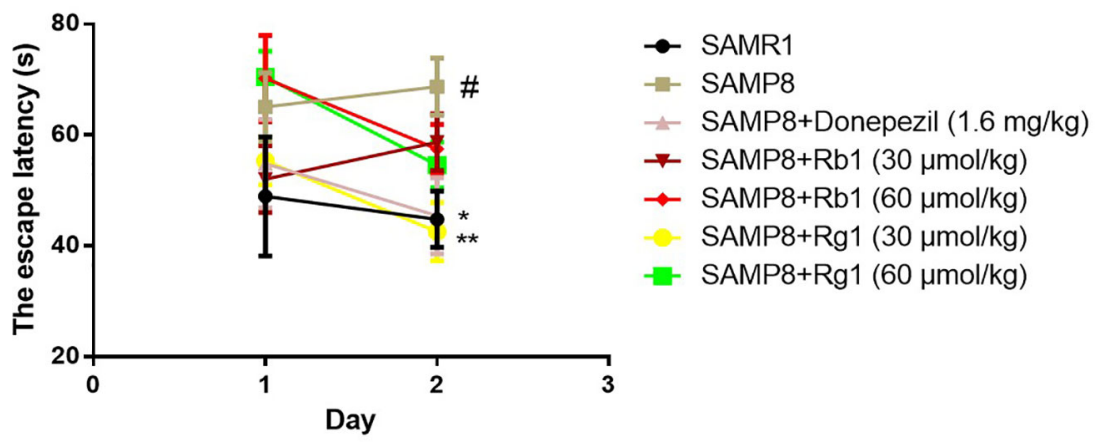

FIGURE 6 | Effects of ginsenosides Rb1 and Rg1 on the relearn ability of SAMP8 mice in the reverse test in MWM test. All data were expressed as the means \pm SEM $(n=8-11) .{ }^{*} p<0.05$ versus the SAM1 group; ${ }^{*} p<0.05,{ }^{* *} p<0.01$ versus the SAMP8 group.

decreased TNF- $\alpha$ concentration compared to the no drug treatment SAMP8 mice $(p<0.01)$. However, treatments with Rg1 (30, $60 \mu \mathrm{mol} / \mathrm{kg}$ ) had no significant effects on TNF- $\alpha$ production in SAMP8 mice, in spite of a tendency to a lower accumulation of this cytokine. In addition, results showed TNF$\alpha$ concentration of $\mathrm{Rb} 1(60 \mu \mathrm{mol} / \mathrm{kg})$ treatment group was lower than that of $\operatorname{Rg} 1(60 \mu \mathrm{mol} / \mathrm{kg})$ treatment group $(p<0.05)$.

In Figure 9, TNF- $\alpha$ concentration were significantly decreased in the $\mathrm{Rb} 1(30,60 \mu \mathrm{mol} / \mathrm{kg})$ or donepezil treatment groups as compared to the SAMP8 group in the cerebral cortex of mice $(p<0.05)$. The SAMP8 group showed a tendency of higher level of TNF- $\alpha$ than that of the SAMR1 group, but no significant difference.

\section{Effects of Ginsenosides Rb1 and Rg1 on Avoiding Neuronal Cells Loss in SAMP8 Mice}

Representative HE staining results in CA1 areas of the hippocampus are shown in Figure 10. In SAMR1 mice, neuronal cells were tightly packed and had large nuclei with clear nucleoli in the hippocampus. In contrast, in SAMP8 group, there were marked morphological changes: neurons were loosely organized and uneven cytoplasm distribution in the hippocampus. In Rg1 or Rb1 treatment group, neuronal cells had large nuclei, and arranged in an orderly manner, indicating that ginsenoside $\mathrm{Rg} 1$ or $\mathrm{Rb} 1$ treatment could reduce the loss of neuronal cells. 

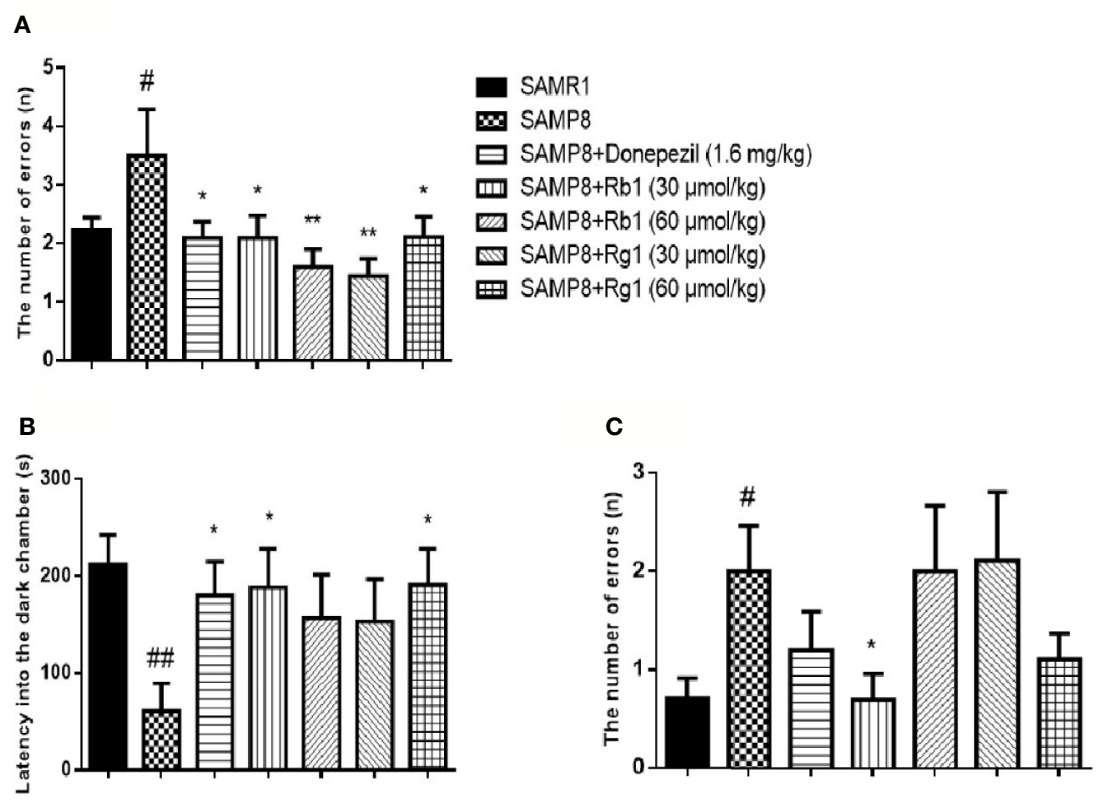

FIGURE 7 | Effects of ginsenosides Rb1 and Rg1 on non-spatial memory deficits in the passive avoidance test in SAMP8 mice. (A) The number of errors; (B) The latency into the dark chamber; (C) The number of errors. All data were expressed as the means \pm SEM $(n=8-10) . " \#<0.05$, ${ }^{\# \#} p<0.01$ versus the SAMR1 group; ${ }^{*} p<0.05,{ }^{* *} p<0.01$ versus the SAMP8 group.

\section{Immunohistochemistry Studies}

\section{Analysis of Microglias Activation}

As shown in Figure 11A, the number of activated microglia cells in the hippocampus of the SAMP8 mice was more than twice of the SAMR1 mice $(p<0.01)$. Microglial cells were brown after being labeled by Iba-1, and activated cells were bigger and intensively stained. Donepezil, Rb1, or Rg1 treatment significantly decreased the number of activated microglia cells in SAMP8 mice (Figure 11B). Compared with the Rb1 treatment, Rg1 treatment showed lower effect on the reduction of the activation of microglia cells in SAMP8 mice.

\section{Analysis of Astrocytes Activation}

Compared with the SAMR1 mice, the activated astrocytes in the hippocampus of the SAMP8 mice were more than doubled ( $p<$ 0.01 , Figure 12). GFAP positive expression cells proliferated significantly, and these cells had larger nuclei and shorter protrusions, and were darkly stained. In the SAMR1 mice, astrocytes were mostly in a non-activated state. After treatment with donepezil, Rb1, or Rg1, the number of activated astrocytes in SAMP8 mice dramatically decreased. The number of activated astrocytes in the $\mathrm{Rb} 1(30 \mu \mathrm{mol} / \mathrm{kg})$ treatment group was significantly lower than that of the Rg1 $(30 \mu \mathrm{mol} / \mathrm{kg})$ treatment group $(p<0.05)$.
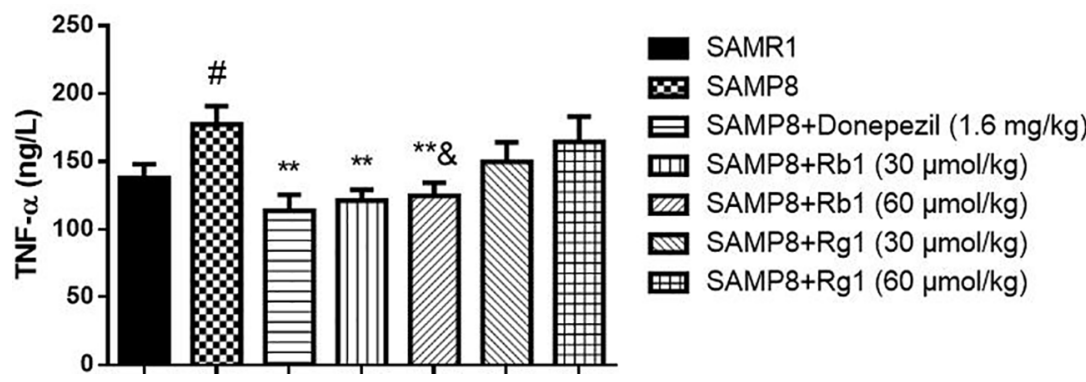

FIGURE 8 | Effects of ginsenosides Rb1 and Rg1 on the TNF- $\alpha$ concentration in the serum of SAMP8 mice. All data were expressed as means \pm SEM ( $\mathrm{n}=6-8)$. ${ }^{\#} p<0.05$ versus the SAMR1 group; ${ }^{\star *} p<0.01$ versus the SAMP8 group; ${ }^{\star} p<0.05$ versus the $\mathrm{Rg} 1(60 \mu \mathrm{mol} / \mathrm{kg}) \mathrm{group}$. 


\section{Effects of Ginsenosides Rb1 and Rg1 on Inhibiting NLRP3 Inflammasome Assembly}

NF-kB-mediated cell signaling is one of the common pathways engaged in the inflammatory response. The expression of p-NFkB-p65 $(p<0.05)$, ASC $(p<, 0.05)$, and caspase-1 $(p<0.05)$ in the hippocampus of SAMP8 mice were twice level as that of SAMR1 mice $(p<0.05)$. Rb1 $(60 \mu \mathrm{mol} / \mathrm{kg})$ treatment could decrease the expression of ASC and caspase-1 in the hippocampus of SAMP8 mice (Figure 13B, $p<0.05$ ).

As shown in Figure 13A, the protein expression of iNOS in SAMP8 mice was more than twice level as that of the SAMR1 mice $(p<0.05)$. Treatment with $\mathrm{Rb} 1(60 \mu \mathrm{mol} / \mathrm{kg})$ or $\operatorname{Rg} 1(30,60$ $\mu \mathrm{mol} / \mathrm{kg})$ significant attenuated this increase in SAMP8 mice $(p$ $<0.05)$.

\section{Effects of Ginsenosides Rb1 and Rg1 on the Accumulation of $A \beta$ in Hippocampus}

As shown in Figure 14, compared with the SAMR1 mice, the protein level of $A \beta$ in the hippocampus of SAMP8 mice was significantly increased three times higher than the former $(p<$ $0.01)$. Rb1 $(30,60 \mu \mathrm{mol} / \mathrm{kg})$ or $\operatorname{Rg} 1(60 \mu \mathrm{mol} / \mathrm{kg})$ treatment significantly reduced the expression of $\mathrm{A} \beta$ in SAMP8 mice $(p<$ 0.01 ), indicating $\mathrm{Rb} 1$ and the high dose of $\operatorname{Rg} 1$ could significantly reduce the accumulation of $A \beta$ in SAMP8 mice. Besides, Rb1(30 $\mu \mathrm{mol} / \mathrm{kg}$ ) has a more prominent inhibitory effect on reducing the protein level of $A \beta$ compared to the same dose of $\operatorname{Rg} 1(p<0.05)$.

\section{DISCUSSION}

Our study showed that ginsenosides Rb1 and Rg1 could ameliorate memory impairments in SAMP8 mice and suggested that their action may be mediated via modulation of NLRP3 inflammasome, decreasing TNF- $\alpha$ level, astrocytes, and microglias activation, ameliorating oxidative stress, and inhibiting expression of p-NF-kB-p65, ASC, caspase-1, and iNOS in hippocampus. Besides, amyloid $\beta$ protein $(\mathrm{A} \beta)$, a major component of the senile plaque, is central to the pathogenesis of $\mathrm{AD}$. Treatments with $\mathrm{Rb} 1$ and $\mathrm{Rg} 1$ significantly reduced the production of $A \beta$ in the brain of SAMP8 mice. In addition, our results showed for the first time that $\mathrm{Rb} 1$ has stronger anti-inflammatory effects than $\mathrm{Rg} 1$ in SAMP8 mice.

The SAMP8 is a classic accelerated aging model mouse (Gao et al., 2019). It shows significant age-related impairment in memory and learning ability (Akiguchi et al., 2017), and demonstrated many pathological features similar to those of $\mathrm{AD}$ patients such as altered amyloid $\beta(\mathrm{A} \beta)$ proteins (Morley et al., 2002), elevated phosphorylation of tau (Canudas et al., 2005), as well as synaptic and dendritic pathological changes (Nomura, 1999). In addition, SAMP8 mice show severe inflammatory reactions and oxidative stress related to aging, which can exacerbate neurological damage and cognitive decline (Jiang et al., 2018; Puigoriol-Illamola et al., 2018). Moreover, compared with same age of SAMR1 mice, SAMP8 mice show significant emotional and memory impairments after six months of age (Shih-Yi et al., 2018). Previous studies exhibited that this strain of mice accelerated aging from 4 months, showing learning and memory disorders, and being in a low-stress and low-terror dementia state with aging (Wang Miyamoto, 1997; Feng et al., 2009). In our study, we found SAMP8 mice showed ageassociated behavioral impairments at 6 months, such as shortterm, long-term, spatial and non-spatial learning, and memory deficits. These results are consistent with previous studies (Miyamoto et al., 1986; Hosokawa et al., 1997). Furthermore, SAMP8 mice at 6 months of age showed poor performance in ORT test (Adler et al., 2014; Jin et al., 2016), and our treatment of Rb1 and Rg1 effectively enhanced DI in both OLR and NOR tests, which coincide with previous study on Rb1 and Rg1, indicating their positvie effects on promote learning and memory in normal animals or animals with cognitive impairment (Qiong et al., 2014). However, our study for the first time demonstrated that both $\mathrm{Rb} 1$ and $\mathrm{Rg} 1$ could significantly ameliorate impaired short-term memory in SAMP8 mice, and the two ginsenosides have similar improvement effects.

MWM test was a classical behavioral method for evaluating the reference, spatial, and working memory of rodents (Meiri and Rosenblu, 1998; Yongliang et al., 2018; Ahmed et al., 2019). It was reported that SAMP8 mice showed spatial memory impairment from 6 months of age (Qin et al., 2008). The results of the acquisition test suggest that the escape latency in the SAMP8 group was significantly longer than the SAMR1 group from day 5 to day 6 , and the number of target crossing decreased in the probe trial. These results indicated that 6month-old SAMP8 mice showed significantly decreased reference memory and long-term spatial memory, compared with the SAMR1 mice. We used the reversal trial to evaluate the reversal learning ability of mice, the reversal learning was significantly damaged in 6-month-old SAMP8 mice, which are in agreement with a previous study (Ding et al., 2019). Many reports have confirmed that both $\mathrm{Rb} 1$ and $\mathrm{Rg} 1$ have neuroprotective effects and can improve cognitive function in AD animal models (Li et al., 2015; Lulin et al., 2017; Wang et al., 2018). Our study demonstrated that Rb1 treatment significantly ameliorated reference memory impairment in SAMP8 mice in the acquisition trial task by shorting the escape latency, but Rg1 treatment showed effectively shortened the latency after training to find the hidden platform. Zhang Juntian used a variety of methods and models to observe the effects of ginseng on the learning and memory in mice, demonstrating that ginsenoside Rg1 can promote memory acquisition, consolidation and reproduction, while $\mathrm{Rb} 1$ mainly improves memory acquisition and reproduction (Zhang, 2000). This study showed that after treatments with $\mathrm{Rb} 1$ and $\mathrm{Rg} 1$ for 8 weeks, Rb1 has a stronger effect than Rg1 on improving the reference memory in SAMP8 mice. Although both Rb1 and Rg1 didn't significantly ameliorate the spatial memory in the probe trial, in the reverse memory test, we found Rg1 could significantly decrease the latency to reach a hidden platform in SAMP8 mice.

The non-spatial memory improvement effect of Rg1 was reported in previous researches, which found $\operatorname{Rg} 1$ improved 


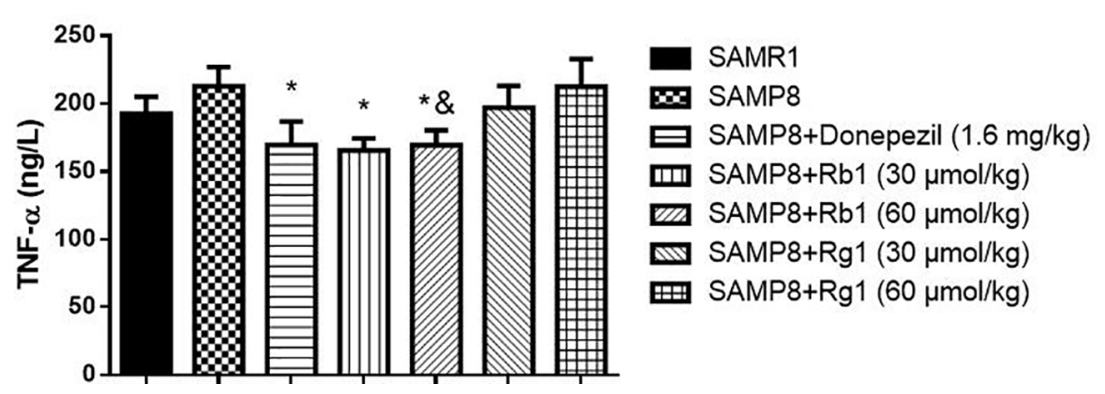

FIGURE 9 | Effects of ginsenosides Rb1 and Rg1 on the TNF- $\alpha$ concentration in the cerebral cortex of SAMP8 mice. All data were expressed as means \pm SEM ( $\mathrm{n}=$ $6-8)$. ${ }^{*} p<0.05$ versus the SAMP8 group; ${ }^{\circledR} p<0.05$ versus the $\mathrm{Rg} 1$ (60 $\mu \mathrm{mol} / \mathrm{kg}$ ) group.

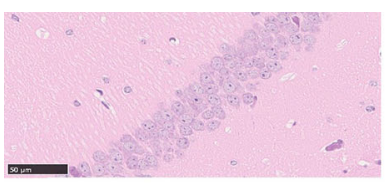

SAMR1

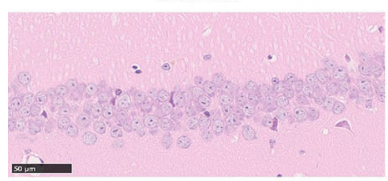

$\mathrm{Rb} 1(30 \mu \mathrm{mol} / \mathrm{kg})$

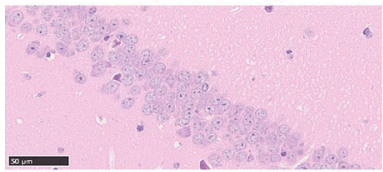

$\operatorname{Rg} 1(30 \mu \mathrm{mol} / \mathrm{kg})$

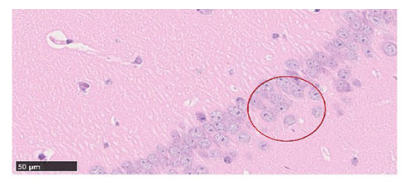

SAMP8

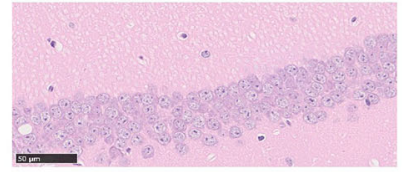

$\mathrm{Rb} 1(60 \mu \mathrm{mol} / \mathrm{kg})$

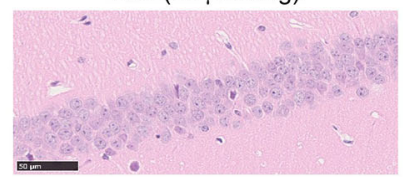

$\operatorname{Rg} 1(60 \mu \mathrm{mol} / \mathrm{kg})$

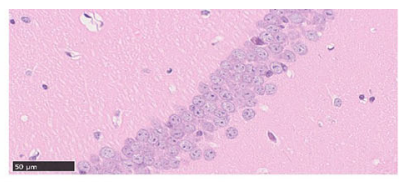

Donepezil $(1.5 \mathrm{mg} / \mathrm{kg})$

FIGURE 10 | Hematoxylin-eosin staining in the CA1 areas in the hippocampus of SAMP8 mice $(\times 400)$. All data were expressed as means \pm SEM $(n=3)$.

scopolamine (SCOP) induced memory impairment in a stepthrough test (Yu-Zhu Wang et al., 2009) and both Rg1 and Rb1 can improve the impaired memory performance induced by SCOP in step-down passive avoidance test (Wang et al., 2010). From the age of four months, SAMP8 mice showed the existence of learning deficits in passive avoidance test (Lourdes et al., 2014; Ren et al., 2018). In this study, the latency enter to the dark chamber of SAMP8 mice was significantly shorter than the SAMR1 mice, which showed for the first time that Rb1 has stronger effects than Rg1 on improving non-spatial memory deficits in SAMP8 mice in the passive avoidance test.

Growing body of evidence indicates that neuroinflammation plays a key role in the prevalence and severity of $\mathrm{AD}$, and its role in the pathogenesis of $\mathrm{AD}$ is even greater than that of senile plaques and nerve fiber entanglements (Heneka et al., 2015). Astrocytes and microglias are the main non-neuronal cells that mediate neuroinflammation (Stephenson et al., 2018). Microglias are belong to the mononuclear phagocyte family and widely considered to be the main immune effectors in the central nervous system (Giulian, 1987). Astrocytes are key regulators of the brain's inflammatory response and reactive astrogliosis is a universally acknowledged feature of AD (Frost and Li, 2017). Activation of astrocytes and microglias result in the production of major proinflammatory cytokines (TNF- $\alpha$, IL-6, or IL-1 $\beta$ ) and neurotoxic factors (reactive oxidative species and tumor necrosis factor- $\alpha$ ), which are typically associated with neurodegenerative diseases including AD (Lull and Block, 2010; Calabrese et al., 2011a). Nuclear factor $-\kappa B(N F-\kappa B)$ is a family of transcription factors that have a crucial role in inflammation, survival, and apoptosis. NF- $\mathrm{KB}$ has been shown to be activate by transcribing the genes encoding pro-inflammatory cytokines, inducible nitric oxide synthase (iNOS), cyclo-oxygenase-1, and cyclo-oxygenase2. All these induced a consequent increase in inflammationmediated signals (Calabrese et al., 2011b; Scuto et al., 2019). A few studies have found that oxidative stress (Baltanás et al., 2013), high levels of inflammation (Ren et al., 2018), activated microglias and astrocytes (Chen et al., 2018) were found in brain tissue of SAMP8 mice, especially the hippocampus. Rb1 and Rg1 were the active ingredients of the root of Panax ginseng C. A. Mayer, which have anti-inflammatory and anti-oxidative stress 
A
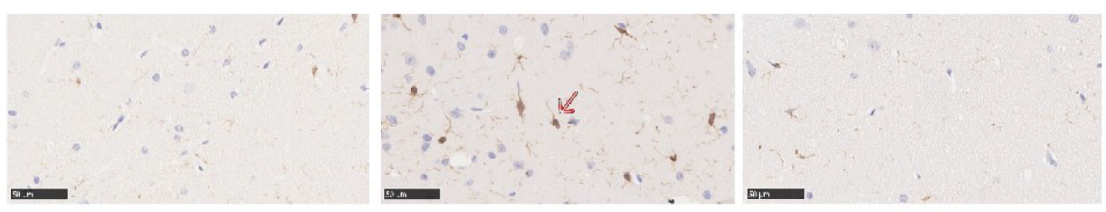

SAMR1

SAMP8

Donepezil (1.5 mg/kg)

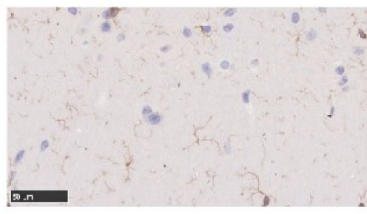

$\mathrm{Rb} 1(30 \mu \mathrm{mol} / \mathrm{kg})$

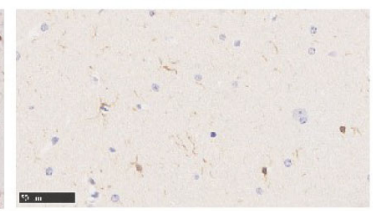

$\mathrm{Rb} 1(60 \mu \mathrm{mol} / \mathrm{kg})$

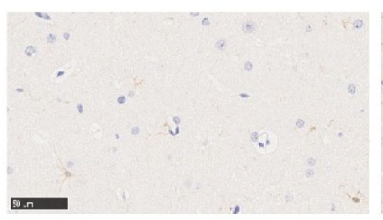

$\operatorname{Rg} 1(30 \mu \mathrm{mol} / \mathrm{kg})$

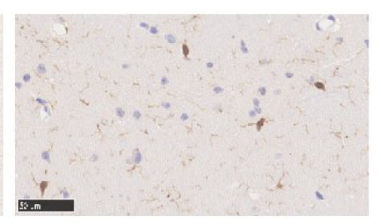

$\operatorname{Rg} 1(60 \mu \mathrm{mol} / \mathrm{kg})$

B

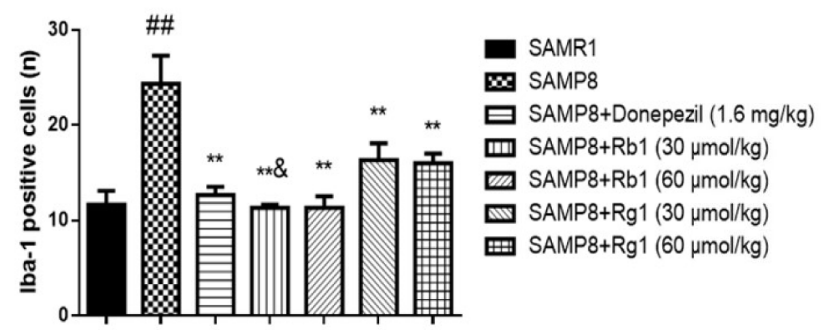

FIGURE 11 | Effects of ginsenosides Rb1 and Rg1 on microglias in the hippocampus of SAMP8 mice. (A) Immunohistochemical staining of Iba-1 in the hippocampus of mice brain $(\times 400)$. (B) The number of lba- 1 positive cells. All data were expressed as means \pm SEM ( $\mathrm{n}=3$ ). \#\# $p<0.01$ versus the SAMR1 group; ${ }^{* \star} p<0.01$ versus the SAMP8 group; ${ }^{\star} p<0.05$ versus the $\mathrm{Rg} 1(30 \mu \mathrm{mol} / \mathrm{kg})$ group.

pharmacological effects (Hui et al., 2017; Xu et al., 2018). Rg1 can decrease the expression of ASC, caspase-1, caspase- 5 , IL-1 $\beta$ in the hippocampus in mice injury induced by chronic glucocorticoids exposure (Zhang et al., 2017). Interestingly, our results showed that administration of Rb1 significantly inhibited the production of TNF- $\alpha$ compared with the SAMP8 mice, while Rg1 couldn't. In addition, our data indicated strong antiinflammatory activity of Rb1 and Rg1 on inhibiting activated microglias and astrocytes in the hippocampus of SAMP8 mice, and $\mathrm{Rb} 1$ has more stronger effects than Rg1. Rb1 is different from Rg1 in chemical structure, Rb1 contains four sugars but Rg1 only has two (Wang et al., 2010). Some reports on the neuroprotective activity of these compounds implied their capacity to cross BBB, but Rb1 and Rg1 showed low capacity to permeate towards the brain. In the in vitro BBB model, ginsenoside Rb1 showed better permeation than Rg1 (Fernández-Moriano et al., 2017). Rb1 mainly regulates stress and Rg1 mainly improves learning and memory (Zhang, 2000). Therefore, in SAMP8 mice, Rb1 still plays a major role in regulation of stress. Our study compared for the first time the effects of two ginsenosides on the improvement of neuroinflammation in SAMP8 mice.

The inflammasome has been identified as a multi-protein complex which plays a key role in innate immune responses against pathogens and toxic metabolites (Nakanishi et al., 2018). Among those types of inflammasomes, NOD-like receptor pyrin domain containing 3 (NLRP3) possesses a critical role in inflammatory response (Li et al., 2018), and associated with many diseases, including AD, Parkinson's disease, diabetes, atherosclerosis, and cerebral ischemia/reperfusion injuries (Guo et al., 2016; Feng et al., 2018; Li et al., 2019; Nasonov and Popkova, 2018; von Herrmann et al., 2018). NLRP3 activation induces aggregation of ASC, leading to caspase-1 activation, promoting the release of inflammatory factors (Stancu et al., 2019). Furthermore, it was reported that $A \beta$ can directly interacted with NLRP3, leading to the activation of the NLRP3 inflammasome, resulting in the activation of caspase-1, and microglial activation (Kayed et al., 2003; Halle et al., 2008). In this study, we found that the expression of ASC and caspase-1 
A

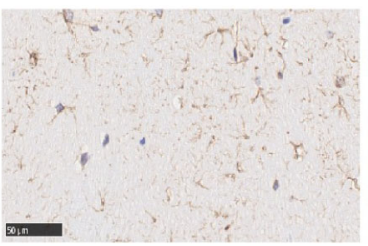

SAMR1

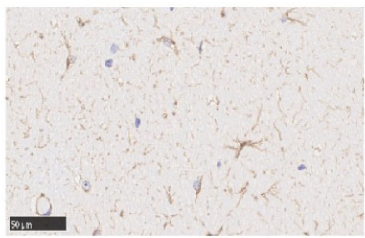

$\mathrm{Rb} 1(30 \mu \mathrm{mol} / \mathrm{kg})$

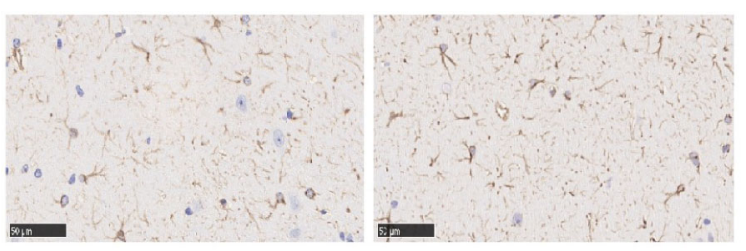

$\operatorname{Rg} 1(30 \mu \mathrm{mol} / \mathrm{kg})$

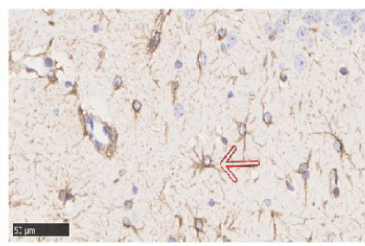

SAMP8

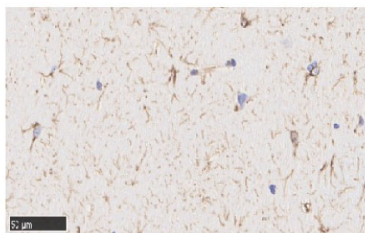

$\mathrm{Rb} 1(60 \mu \mathrm{mol} / \mathrm{kg})$

$\operatorname{Rg} 1(60 \mu \mathrm{mol} / \mathrm{kg})$

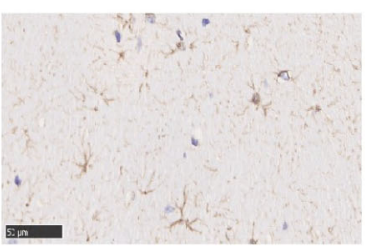

Donepezil $(1.5 \mathrm{mg} / \mathrm{kg})$

B

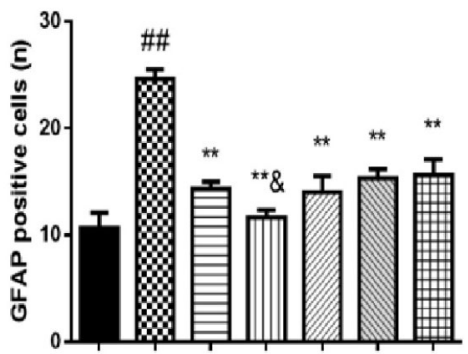

SAMR1

జ SAMP8

ㄱAMP8+Donepezil (1.6 mg/kg)

피 SAMP8+Rb1 $(30 \mu \mathrm{mol} / \mathrm{kg})$

ש2 SAMP8+Rb1 $(60 \mu \mathrm{mol} / \mathrm{kg})$

a SAMP8+Rg1 $(30 \mu \mathrm{mol} / \mathrm{kg})$

WAMP8+Rg1 (60 $\mathrm{mol} / \mathrm{kg})$

FIGURE 12 | Effects of ginsenosides Rb1 and Rg1 on astrocytes in the hippocampus of SAMP8 mice. (A) Immunohistochemical staining of GFAP in the hippocampus of mice brain ( $\times 400)$. (B) The number of GFAP positive cells. All data were expressed as means \pm SEM $(n=3)$. ${ }^{\# \# ~} p<0.01$ versus the SAMR1 group; ${ }^{* *} p<0.01$ versus the SAMP8 group; ${ }^{*} p<0.05$ versus the $\mathrm{Rg} 1(30 \mu \mathrm{mol} / \mathrm{kg})$ group.

in the hippocampus of SAMP8 mice were significant increased, these are consistent with the findings of Jing Jiang (Jiang et al., 2018) and Ning Ding (Ning et al., 2017). The iNOS in the central nervous system is pathologic and plays an important role in neuroinflammation (Kim et al., 2018). Increasing iNOS expression was found in cultured astrocytes by $\mathrm{A} \beta$, and it could result in excessive production of $\mathrm{NO}$, causing neuronal damage and death (Wang et al., 2017). In our results, the protein level of iNOS in the hippocampus of Rb1 and Rg1 treatment mice were lower than that of the SAMP8 mice, which suggest $\mathrm{Rb} 1$ and Rg1 could inhibit the neuroinflammation in SAMP8 mice. The accumulations of $\mathrm{A} \beta$ were found in $\mathrm{AD}$ animal models, such as aging mice (Li et al., 2016), transgenic mice with $\mathrm{AD}$ (Dionísio et al., 2015), and over-expression of $\mathrm{A} \beta$ is often one of the important factors that promote chronic inflammation and oxidative stress in the brain (Batarseh et al. 2016). Our results showed the significant increase of $A \beta$ expression in the hippocampus of SAMP8 mice, indicating the neuroinflammation associated with overexpression of $A \beta$. We found $\mathrm{Rb} 1$ and $\operatorname{Rg} 1$ treatment could decrease the overexpression of $\mathrm{A} \beta$. Previous researches demonstrated that Rg1 may involve in the activation of Akt/ERK $1 / 2$ and PKA/CREA signaling pathways, and the signal-regulated NF-kB/NO signaling pathways, enhance neurite outgrowth and protect against $A \beta$ induced damage (Huang et al., 2016; Wu et al., 2016; Hejian et al., 2019). Rb1 could improve cognitive and memory functions by inhibiting the levels of pro-apoptosis mediators and improving the levels of anti-apoptosis mediators in the rat model of $\mathrm{AD}$ induced by $\mathrm{A} \beta$ 1-40 (Wang et al., 2018). In addition, Rb1 showed a significant effect in reducing caspase-1 


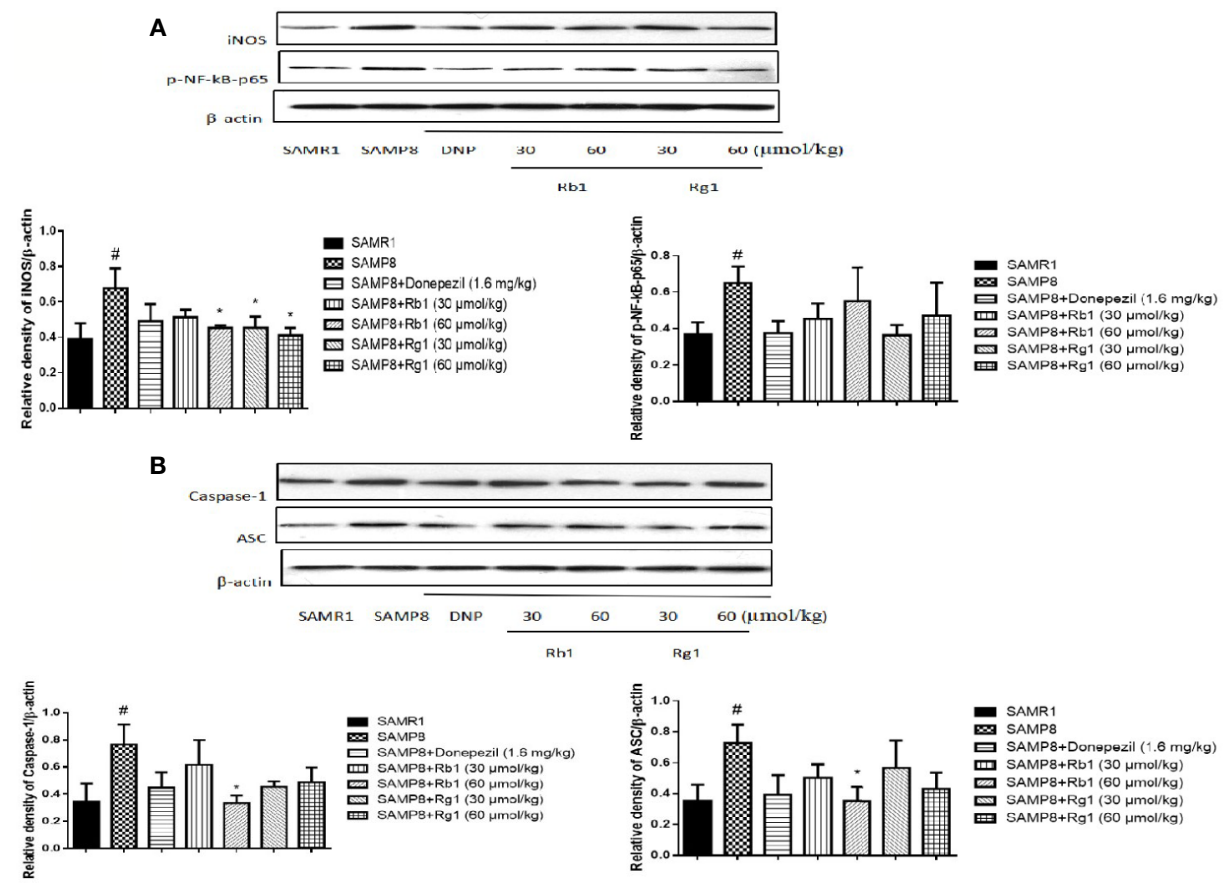

FIGURE 13 | Effects of ginsenosides Rb1 and Rg1 on the protein levels of p-NF-kB-p65, ASC, caspase-1, iNOS in the hippocampus of SAMP8 mice. (A) Protein expression and gray intensity analysis of p-NF-kB-p65 and iNOS; (B) Protein expression and gray intensity analysis of ASC and caspase-1. All data were expressed as means \pm SEM $(n=3) .{ }^{\#} p<0.05$ versus the SAMR1 group; ${ }^{*} p<0.05$ versus the SAMP8 group.
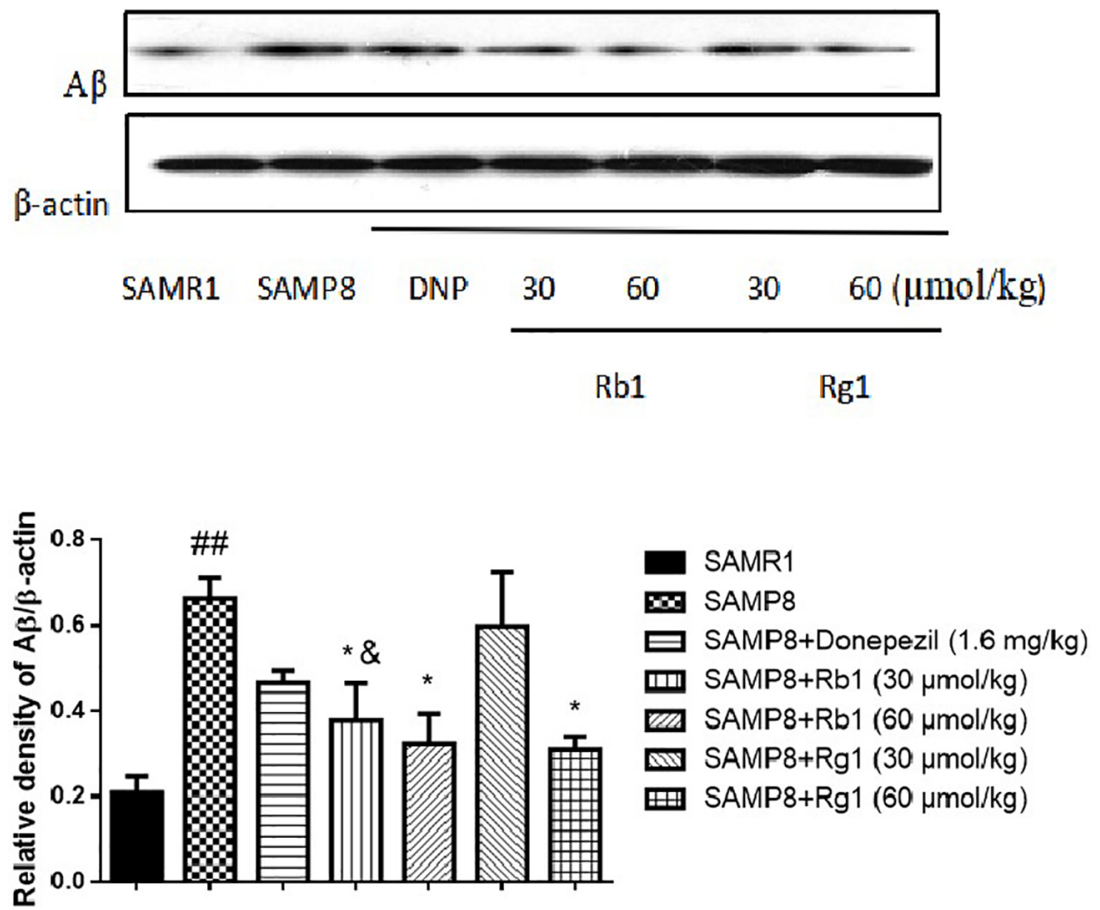

FIGURE 14 | Effects of ginsenosides Rb1 and Rg1 on the protein level of A $\beta$ in the hippocampus of SAMP8 mice. All data were expressed as means \pm SEM $(n=$ 3). ${ }^{\# \#} p<0.01$ versus the SAMR1 group; ${ }^{*} p<0.05$ versus the SAMP8 group; ${ }^{\circledR} p<0.05$ versus the $\mathrm{Rg} 1(30 \mu \mathrm{mol} / \mathrm{kg})$ group. 
and ASC protein expression, indicating $\mathrm{Rb} 1$ can regulate the inflammatory reaction in the brain by inhibiting ASC and caspase-1.

In summary, although there are several studies have reported that $\mathrm{Rg} 1$ and $\mathrm{Rb} 1$ are both effective in improving memory impairment of AD animal models, especially in SAMP8 mice, there was no report regarding the different protective effects of Rg1 and Rb1 in facilitating neuroinflammation of SAMP8 mice at the same dosage level. Our present study demonstrated that: (1) Rb1 and Rg1 have similarly effects on improving the shortterm, spatial and non-spatial memory in SAMP8 mice. (2) Rg1 was more effective than Rb1 in improving escape acquisition and reverse memory deficiency in SAMP8 mice. (3) For the first time, we found that $\mathrm{Rb} 1$ has stronger effects than $\mathrm{Rg} 1$ on improving non-spatial memory in SAMP8 mice. (4) Rb1 showed stronger effects than the same dose of $\mathrm{Rg} 1$ in inhibiting glial cell activation, the accumulation of A $\beta$ and NLRP3 inflammasome relative protein in the hippocampus of SAMP8 mice. (5) Rg1 was more effective than Rb1 in inhibiting the expression of iNOS in the brain of SAMP8 mice. These results indicated that Rb1 might be more potent than Rg1 on improving the acquisition impairment and has stronger effect in inhibit neuroinflammation. However, further study needed to do in order to make better explanation the difference of $\mathrm{Rg} 1$ and $\mathrm{Rb} 1$ in cognitive enhancement.

\section{DATA AVAILABILITY STATEMENT}

All data generated for this study are included in the article.

\section{ETHICS STATEMENT}

The animal study was reviewed and approved by the Care and Use of Laboratory Animals of IMPLAD, CAMS \& PUMC, China (SLXD-20181225051). The animal study was reviewed and

\section{REFERENCES}

Adler, B. L., Yarchoan, M., Hwang, H. M., Louneva, N., Blair, J. A., and Palm, R. (2014). Neuroprotective effects of the amylin analogue pramlintide on alzheimer"s disease pathogenesis and cognition. Neurobiol. Aging 35 (4), 793-801. doi: 10.1016/j.neurobiolaging.2013.10.076

Ahmed, A., Zeng, G., Jiang, D., Lin, H., and Wang, Q. (2019). Time-dependent impairments in learning and memory in streptozotocin-induced hyperglycemic rats. Metab. Brain Dis. 34 (1), 1431-1446. doi: 10.1007/s11011-019-00448-7

Akiguchi, I., Pallàs, Me., Budka, H., Akiyama, H., Ueno, M., Han, J., et al. (2017). SAMP8 mice as a neuropathological model of accelerated brain aging and dementia: Toshio Takeda"s legacy and future directions. Neuropathology 37, 293-305. doi: 10.1111/neup.12373

Aragão, W. A. B., Teixeira, F. B., Fagundes, N. C. F., Fernandes, R. M., Fernandes, L. M. P., da Silva, M. C. F., et al. (2018). Hippocampal Dysfunction Provoked by Mercury Chloride Exposure: Evaluation of Cognitive Impairment, Oxidative Stress, Tissue Injury and Nature of Cell Death. Oxid. Med. Cell Longev. 2018, 7878050. doi: 10.1155/2018/7878050

Baltanás, A., Solesio, M. E., Zalba, G., Galindo, M. F., Fortuño, A., and Jordán, J. (2013). The senescence-accelerated mouse prone-8 (sam-p8) oxidative stress is associated with upregulation of renal nadph oxidase system. J. Physiol. Biochem. 69 (4), 927-935. doi: 10.1007/s13105-013-0271-6 approved by the Care and Use of Laboratory Animals of IMPLAD, CAMS \& PUMC, China (SLXD-20181225051).

\section{AUTHOR CONTRIBUTIONS}

The authors contributed in the following way: YY performed experiments, wrote manuscript and analyzed data; SL drafted the first version of the manuscript; $\mathrm{HH}$ and JL offered experimental help; YL analyzed part of the data; SC and AP revised the manuscript; XL and QW designed the study and revised the manuscript. All authors have read and approved the final manuscript.

\section{FUNDING}

This work was supported by the National Key Research and Development Program of China (2016YFE0131800), Science \& Technology department of Sichuan province (2019YFH0023), Office of Sciences \& Technology and Talent work of Luzhou (2018LZXNYD-ZK32), the High - end Talents Recruitment Program (Liu Xinmin group) of Luzhou Municipal People's Government.

\section{ACKNOWLEDGMENTS}

We should thank the opening foundation of the State Key Laboratory of Space Medicine Fundamentals and Application, Chinese Astronaut Research and Training Center; the National Key Research and Development Program of China; and the High end Talents Recruitment Program (Liu Xinmin group) of Luzhou Municipal People's Government for the financial support. We would like to thank Dr. Betty Yuen-Kwan Law, Macau University of Science and Technology, Taipa, Macau, for her kind help to revise the manuscript.

Batarseh, Y. S., Duong, Q.-V., Mousa, Y. M., Al Rihani, S. B., Elfakhri, K., and Kaddoumi, A. (2016). Amyloid- $\beta$ and Astrocytes Interplay in Amyloid- $\beta$ Related Disorders. IJMS 17, 338. doi: 10.3390/ijms17030338

Boumenir, A., Cognat, E., Sabia, S., Hourregue, C., Lilamand, M., Dugravot, A., et al. (2019). CSF level of $\beta$-amyloid peptide predicts mortality in Alzheimer's disease. Alzheimer's Res. Ther. 11, 29. doi: 10.1186/s13195019-0481-4

Calabrese, V., Cornelius, C., Dinkova-Kostova, A. T., Iavicoli, I., and Calabrese, E. J. (2011a). Cellular stress responses, hormetic phytochemicals and vitagenes in aging and longevity. Biochim. Biophys. Acta 1822 (5), 753-783. doi: 10.1016/ j.bbadis.2011.11.002

Calabrese, V., Cornelius, C., Cuzzocrea, S., Iavicoli, I., Rizzarelli, E., and Calabrese, E. J. (2011b). Hormesis, cellular stress response and vitagenes as critical determinants in aging and longevity. Mol. Asp. Med. 32 (4-6), 0-304. doi: 10.1016/j.mam.2011.10.007

Canudas, A. M., Gutierrez-Cuesta, J., Rodriguez, M. I., Acuna-Castroviejo, D., Sureda, F. X., Camins, A., et al. (2005). Hyperphosphorylation of microtubuleassociated protein tau in senescence-accelerated mouse (SAM). Mech. Ageing Dev. 126, 1300-1304. doi: 10.1016/j.mad.2005.07.008

Chen, W., Liang, T., Zuo, W., Wu, X., Shen, Z., Wang, F., et al. (2018). Neuroprotective effect of 1-Deoxynojirimycin on cognitive impairment, $\beta$ - 
amyloid deposition, and neuroinflammation in the SAMP8 mice. BioMed. Pharmacother. 106, 92-97. doi: 10.1016/j.biopha.2018.06.106

Ding, N., Jiang, J., Xu, A., Tang, Y., and Li, Z. (2019). Manual Acupuncture Regulates Behavior and Cerebral Blood Flow in the SAMP8 Mouse Model of Alzheimer's Disease. Front. Neurosci. 13, 37. doi: 10.3389/fnins.2019.00037

Dionísio, P. A., Amaral, J. D., Ribeiro, M. F., Lo, A. C., D'Hooge, R., and Rodrigues, C. M. P. (2015). Amyloid- $\beta$ pathology is attenuated by tauroursodeoxycholic acid treatment in app/ps1 mice after disease onset. Neurobiol. Aging 36 (1), 228-240. doi: 10.1016/j.neurobiolaging.2014.08.034

Ennaceur, A., Michalikova, S., and Chazot, P. L. (2009). Do rats really express neophobia towards novel objects? Experimental evidence from exposure to novelty and to an object recognition task in an open space and an enclosed space. Behav. Brain Res. 197, 417-434. doi: 10.1016/j.bbr.2008.10.007

Feng, W., Hong, C., Miao, Y., and Xiaohong, S. (2009). Age-related behavior changes of senescence accelerated mouse. Chin. J. Gerontol. 29 (6), 671-674. doi: CNKI:SUN:ZLXZ.0.2009-06-015

Feng, J., Wang, J. X., Du, Y. H., Liu, Y., Zhang, W., Chen, J. F., et al. (2018). Dihydromyricetin inhibits microglial activation and neuroinflammation by suppressing nlrp3 inflammasome activation in app/ps1 transgenic mice. CNS Neurosci. Ther. 24 (12), 1207-1218. doi: 10.1111/cns.12983

Fernández-Moriano, C., González-Burgos, E., Iglesias, I., Lozano, R., and GómezSerranillos, M.P. (2017). Evaluation of the adaptogenic potential exerted by ginsenosides $\mathrm{rb} 1$ and $\mathrm{rg} 1$ against oxidative stress-mediated neurotoxicity in an in vitro neuronal model. PloS One 12 (8), e0182933. doi: 10.1371/ journal.pone. 0182933

Frost, G. R., and Li, Y. M. (2017). The role of astrocytes in amyloid production and alzheimer"s disease. Open Biol. 7 (12), 170228. doi: 10.1098/rsob.170228

Gao, S., Zhang, X., Song, Q., Liu, J., Ji, X., and Wang, P. (2019). POLD1 deficiency is involved in cognitive function impairment in AD patients and SAMP8 mice. Biomed. Pharmacother. 114, 108833. doi: 10.1016/j.biopha.2019.108833

Giulian, D. (1987). Ameboid microglia as effectors of inflammation in the central nervous system. J. Neurosci. Res. 18 (1), 155-171. doi: 10.1002/jnr.490180123

Guo, Z., Yu, S., Chen, X., Ye, R., Zhu, W., and Liu, X. (2016). NLRP3 Is Involved in Ischemia / Reperfusion Injury. CNS Neurol. Disord. Drug Targets CNS Neurol. Disord. Drug Targets 15 (6), 699-712. doi: 10.2174/187152731566 6160321111829

Halle, A., Hornung, V., Petzold, G. C., Stewart, C. R., Monks, B. G., Reinheckel, T., et al. (2008). The NALP3 inflammasome is involved in the innate immune response to amyloid-beta. Nat. Immunol. 9, 857-865. doi: 10.1038/ni.1636

Hejian, L., Hong, L., Yu, J., and Wensheg, Z. (2019). Advances in Research on Drug Efficacy and Mechanism of Ginsenoside Rg1 and Rb1. J. Wuhan Univ.(Nat. Sci. Ed.) 65 (04), 323-332. doi: 10.14188/j.1671-8836.2019.04.001

Heneka, M. T., Carson, M. J., Khoury, J. E., Landreth, G., Brosseron, F., Feinstein, D. L., et al. (2015). Neuroinflammation in Alzheimer's Disease. Lancet Neurol. 14 (4), 388-405. doi: 10.1016/S1474-4422(15)70016-5

Hosokawa, M., Abe, T., Higuchi, K., Shimakawa, K., Omori, Y., Matsushita, T., et al. (1997). Management and design of the maintenance of SAM mouse strains: an animal model for accelerated senescence and age-associated disorders. Exp. Gerontol. 32 (1), 111-116. doi: 10.1016/S0531-5565(96) 00078-2

Huang, L., Liu, L., Liu, J., Dou, L., Wang, G., Liu, X., et al. (2016). Ginsenoside Rg1 protects against neurodegeneration by inducing neurite outgrowth in cultured hippocampal neurons. Neural Regener. Res. 11 (02), 319-325. doi: CNKI:SUN: SJZY.0.2016-02-035

Hui, M. H., Ye, Z., Nan, D. G., Xiao, H. F., Peng, D., and Ming, T. (2017). Ginsenoside $\mathrm{rb} 1$ attenuates isoflurane / surgery-induced cognitive dysfunction via inhibiting neuroinflammation and oxidative stress. Biomed. Environ. Sci. 5, 53-62. doi: CNKI:SUN:SWYX.0.2017-05-006

Jiang, J., Ding, N., Wang, K., and Li, Z. (2018). Electroacupuncture Could Influence the Expression of IL-1 $\beta$ and NLRP3 Inflammasome in Hippocampus of Alzheimer's Disease Animal Model. Evidence-Based Complement. Altern. Med. 2018 (11), 1-7. doi: 10.1155/2018/8296824

Jin, G., Yin, S., Yang, Z., Zou, D., Zhang, Z., Li, X., et al. (2016). Silibinin rescues learning and memory deficits by attenuating microglia activation and preventing neuroinflammatory reactions in samp8 mice. Neurosci. Lett. 629, 256-261. doi: 10.1016/j.neulet.2016.06.008

Jinfeng, L., Kun, N., Zhenjie, L., Sisi, X., Ying, Z., Jinping, S., et al (2013) Improvements of MorrisWater Maze Evaluation Method and Re -evaluation of the Rapid Aaging De mentia SAMP8 Cognitive Function in Mice. J. Tradit. Chin. Med. 22 (3), 5-7, 22.

Kayed, R., Head, E., Thompson, J. L., McIntire, T. M., Milton, S. C., Cotman, C. W., et al. (2003). Common structure of soluble amyloid oligomers implies common mechanism of pathogenesis. Science 300, 486-489. doi: 10.1126/science.1079469

Kim, M. E., Jung, I., Na, J. Y., Lee, Y., Lee, J., Lee, J. S., et al. (2018). Pseudane-VII Regulates LPS-Induced Neuroinflammation in Brain Microglia Cells through the Inhibition of iNOS Expression. Molecules 23 (12), 3196. doi: 10.3390/ molecules 23123196

Kima, N., Martínezb, C. C., Janga, D. S., Leec, J. K., and Oh, M. S. (2019). Anti neuroinflammatory effect of Iresine celosia on lipopolysaccharide - stimulated microglial cells and mouse. Biomed. Pharmacother. 111, 1359-1366. doi: 10.1016/j.biopha.2019.01.017

Lamarão-Vieira, K., Pamplona-Santos, D., Nascimento, P. C., Corrêa, M. G., and Bittencourt, L. O. (2019). Physical Exercise Attenuates Oxidative Stress and Morphofunctional Cerebellar Damages Induced by the Ethanol Binge Drinking Paradigm from Adolescence to Adulthood in Rats. Oxid. Med. Cell. Longevity. 1-14. doi: 10.1155/2019/6802424

Lane, A., Hardy, J., and Schott, J. M. (2018). Alzheimer's disease. Eur. J. Neurol. 25 (1), 59-70. doi: 10.1111/ene.13439

Li, N., Zhou, L., Li, W., Liu, Y., Wang, J., and He, P. (2015). Protective effects of ginsenosides $\mathrm{rg} 1$ and $\mathrm{rbl}$ on an alzheimer"s disease mouse model: a metabolomics study. J. Chromatogr. B 985, 54-61. doi: 10.1016/ j.jchromb.2015.01.016

Li, F., Wu, X., Li, J., and Niu, Q. (2016). Ginsenoside rg1 ameliorates hippocampal long-term potentiation and memory in an alzheimer"s disease model. Mol. Med. Rep. 13 (6). doi: 10.3892/mmr.2016.5103

Li, S. J., Zhang, Y. F., Ma, S. H., Yi, Y., Yu, H. Y., Pei, L., et al. (2018). The role of NLRP3 inflammasome in stroke and central poststroke pain. Med. (Baltimore) 97 (33), e11861. doi: 10.1097/MD.0000000000011861

Li, S., Liu, R., Xue, M., Qiao, Y., Chen, Y., Long, G., et al. (2019). Spleen tyrosine kinase-induced JNK-dependent NLRP3 activation is involved in diabetic cardiomyopathy. Int. J. Mol. Med. 43 (6), 2481-2490. doi: 10.3892/ ijmm.2019.4148

Lourdes, O., Barros-Miñones, L., Joaquin, J., Angel, C. M., Tordera, R. M., Norberto, A., et al. (2014). Sildenafil decreases bacel and cathepsin b levels and reduces app amyloidogenic processing in the samp8 mouse. J. Gerontol. Ser. A: Biomed. Sci. Med. Sci. 70 (6), 675-685. doi: 10.1093/gerona/glu106

Lu, C., Dong, L., Lv, J., Wang, Y., Fan, B., Wang, F., et al. (2018a). The protective effect of 20 (s)-protopanaxadiol (ppd) against chronic sleep deprivation (csd)induced memory impairments in mice. Brain Res. Bull. 137, 249-256. doi: 10.1016/j.brainresbull.2017.12.012

Lu, C., Lv, J., Dong, L., Jiang, N., Wang, Y., Wang, Q., et al (2018b). Neuroprotective effects of 20(s)-protopanaxatriol (ppt) on scopolamineinduced cognitive deficits in mice. Phytother Res. Ptr. 2018, 1-8. doi: 10.1002/ptr.6044

Lulin, N., Junxia, X., Honglian, L., Zaijun, Z., Ying, Y., Xinfeng, H., et al. (2017). Ginsenoside $\operatorname{rg} 1$ ameliorates behavioral abnormalities and modulates the hippocampal proteomic change in triple transgenic mice of alzheimer's disease. Oxid. Med. Cell. Longevity 24, 1-17. doi: 10.1155/2017/6473506

Lull, E., and Block, M. L. (2010). Microglial activation and chronic neurodegeneration. Neurotherapeutics 7 (4), 354-365. doi: 10.1016/ j.nurt.2010.05.014

Meiri, N., and Rosenblu, N. (1998). Lateral ventricle injection of the protein synthesis inhibit oranisomyc in impairs long-term memory in a spatial memory task. Brain Res. 789, 48-55. doi: 10.1016/S0006-8993(97)01528-X

Miyamoto, M., Kiyota, Y., Yamazaki, N., Nagaoka, A., Matsuo, T., Nagawa, Y., et al. (1986). Age-related changes in learning and memory in the senescenceaccelerated mouse (SAM). Physiol. Behav. 38, 399-406. doi: 10.1016/0031-9384 (86)90112-5

Miyamoto, M. (1997). Characteristics of age-related behavioral changes in senescence-accelerated mouse SAMP8 and SAMP10. Exp. Gerontol. 32 (1-2), 139-148. doi: 10.1016/S0531-5565(96)00061-7

Morley, J. E., Farr, S. A., and Flood, J. F. (2002). Antibody to amyloid beta protein alleviates impaired acquisition, retention, and memory processing in SAMP8 mice. Neurobiol. Learn. Mem. 78, 125-138. doi: 10.1006/nlme.2001.4047

Nakanishi, A., Kaneko, N., Takeda, H., Sawasaki, T., Morikawa, S., Zhou, W., et al. (2018). Amyloid $\beta$ directly interacts with nlrp3 to initiate inflammasome 
activation: identification of an intrinsic nlrp3 ligand in a cell-free system. Inflammation Regener. 38 (1), 27. doi: 10.1186/s41232-018-0085-6

Nasonov, E. L., and Popkova, T. V. (2018). Atherosclerosis: perspectives of antiinflammatory therapy. Ter. Arkh. 11, 90 (5), 4-12. doi: 10.26442/terarkh 201890514-12

Ning, D., Jing, J., Menghan, L., Jiatong, H., Yiyuan, X., Xiaoxiao, L., et al. (2017). Manual acupuncture suppresses the expression of proinflammatory proteins associated with the nlrp3 inflammasome in the hippocampus of samp8 mice. Evidence-Based Complement. Altern. Med. 2017, 1-8. doi: 10.1155/2017/ 3435891

Nomura, Y. Y. (1999). Okuma Age-related defects in lifespan and learning ability in SAMP8 mice. Neurobiol. Aging 20, 111-115. doi: 10.1016/S0197-4580(99) 00006-8

Puigoriol-Illamola, D., Griñán-Ferré, C., Vasilopoulou, F., Leiva, R., Vázquez, S., and Pallàs, M. (2018). 11ß-HSD1 Inhibition by RL-118 Promotes Autophagy and Correlates with Reduced Oxidative Stress and Inflammation, Enhancing Cognitive Performance in SAMP8 Mouse Model. Mol. Neurobiol. 55 (12), 8904-8915. doi: 10.1007/s12035-018-1026-8

Qin, C., Jian-chun, Y., Jian-ming, P., Tao, Y., and Jing-xian, H. (2008). Age-related Changes in Behavior of Senescence Accelerated Mouse SAMP8. Prog. Mod. Biomed. 8 (10), 1801-1804. doi: 10.13241/j.cnki.pmb.2008.10.021

Qiong, W., Yi, W., Chunyoung, H., and Xinmin, L. (2014). Nootropic effect of gensenosides Rg1 and Rb1 and their metabolites. Chin. Tradit. Herbal Drugs 45 (13), 1960-1965. doi: 10.7501/j.issn.0253-2670.2014.13.025

Quan, Q. K., Wang, J., Li, X., and Wang, Y. (2013). Ginsenoside Rg1 Decreases A $\beta 1-42$ Level by Upregulating PPAR $\gamma$ and IDE Expression in the Hippocampus of a Rat Model of Alzheimer's Disease. PloS One 8 (3), e59155. doi: 10.1371/journal.pone.0059155

Razgonova, M. P., Veselov, V. V., Zakharenko, A. M., Sergeyevich Golokhvast, K., Evgenyevich Nosyrev, A., and Cravotto, G. (2019). Panax ginseng components and the pathogenesis of Alzheimer's disease. Mol. Med. Rep. 19 (4), 2975-2998. doi: $10.3892 / \mathrm{mmr} .2019 .9972$

Ren, H. L., Lv, C. N., Xing, Y., Geng, Y., Zhang, F., Bu, W., et al. (2018). Downregulated nuclear factor e2-related factor 2 (nrf2) aggravates cognitive impairments via neuroinflammation and synaptic plasticity in the senescenceaccelerated mouse prone 8 (samp8) mouse: a model of accelerated senescence. Med. Sci. Monitor Int. Med. J. Exp. Clin. Res. 24, 1132-1144. doi: 10.12659/ MSM.908954

Scuto, M. C., Mancuso, C., Tomasello, B., Ontario, M. L., and Calabrese, V. (2019). Curcumin, hormesis and the nervous system. Nutrients 11 (10), 2417. doi: $10.3390 /$ nu11102417

Shih-Yi, H., Li-Han, C., Ming-Fu, W., Chih-Chieh, H., Ching-Hung, C., Jia-Xian, L., et al. (2018). Lactobacillus paracasei PS23 Delays Progression of AgeRelated Cognitive Decline in Senescence Accelerated Mouse Prone 8 (SAMP8) Mice. Nutrients 10 (7), 894. doi: 10.3390/nu10070894

Stancu, I. C., Cremers, N., Vanrusselt, H., Couturier, J., and Dewachter, I. (2019). Aggregated tau activates nlrp3-asc inflammasome exacerbating exogenously seeded and non-exogenously seeded tau pathology in vivo. Acta Neuropathologica (Suppl 1) 137(4), 599-617. doi: 10.1007/s00401-01801957-y

Stephenson, J., Nutma, E., van der Valk, P., and Amor, S. (2018). Inflammation in CNS neurodegenerative diseases. Immunology 154(2), 204-219. doi: 10.1111/ imm. 12922

von Herrmann, K. M., Salas, L. A., Martinez, E. M., Young, A. L., Howard, J. M., Feldman, M. S., et al (2018). NLRP3 expression in mesencephalic neurons and characterization of a rare NLRP3 polymorphism associated with decreased risk of Parkinson's disease. NPJ Parkinsons Dis. 4, 24. doi: 10.1038/s41531-018-0061-5

Wang, Y.-Z., Chen, J., Chu, S.-F., Wang, Y.-S., Wang, X.-Y., Chen, N.-H., et al. (2009). Improvement of Memory in Mice and Increase of Hippocampal Excitability in Rats by Ginsenoside Rgl's Metabolites Ginsenoside Rh1 and Protopanaxatriol. J. Pharmacol. Sci. 109 (4), 504-510. doi: 10.1254/ jphs.08060FP

Wang, Q., Sun, L. H., Jia, W., Liu, X. M., Dang, H. X., Mai, W. L., et al. (2010). Comparison of ginsenosides $\mathrm{Rg} 1$ and $\mathrm{Rb} 1$ for their effects on improving scopolamine-induced learning and memory impairment in mice. Phytother. Res. 24 (12), 1748-1754. doi: 10.1002/ptr.3130
Wang, Q., Zhang, Y. L., Li, Y. H., Chen, S. G., Gao, J. H., Chen, Y. X., et al. (2016). The memory enhancement effect of Kai Xin San on cognitive deficit induced by simulated weightlessness in rats. J. Ethnopharmacol. 187, 9-16. doi: 10.1016/ j.jep.2015.12.029

Wang, S. S., Jia, J., and Wang, Z. (2017). Mesenchymal Stem Cell-Derived Extracellular Vesicles Suppresses iNOS Expression and Ameliorates Neural Impairment in Alzheimer's Disease Mice. J. Alzheimer"s Dis. 61 (4 Suppl), 1-9. doi: 10.3233/JAD-170848

Wang, Y., Li, Y., Yang, W., Gao, S., and Hu, H. (2018). Ginsenoside rb1 inhibit apoptosis in rat model of alzheimer's disease induced by aß1-40. Am. J. Trans. Res. 10 (3), 796-805.

Wu, J., Yang, H., Zhao, Q., Zhang, X., and Lou, Y. (2016). Ginsenoside rg1 exerts a protective effect against a 325 -35-induced toxicity in primary cultured rat cortical neurons through the nf-kb/no pathway. Int. J. Mol. Med. 37 (3), 781-788. doi: 10.3892/ijmm.2016.2485

Xingxing, H., and Tao, L. (2018). Research progresses and the effection of traditional Chinese medicine of pyroptosis and Alzheimer disease. J. Med. Postgraduates 31 (12), 1319-1324. doi: 10.16571/j.cnki.1008-8199.2018.12.020

Xu, T.-Z., Shen, X.-Y., Sun, L.-L., Chen, Y.-L., Zhang, B.-Q., Huang, D.-K., et al. (2018). Ginsenoside Rg1 protects against $\mathrm{H} 2 \mathrm{O} 2$-induced neuronal damage due to inhibition of the NLRP1 inflammasome signalling pathway in hippocampal neurons in vitro. Int. J. Mol. Med. 43 (2), 717-726. doi: 10.3892/ijmm.2018.4005

Yang, Y., Jia, X., Feng, J., Wang, Z., Cao, Y., Liu, J., et al. (2017). Fuzheng Quxie Decoction Ameliorates Learning and Memory Impairment in SAMP8 Mice by Decreasing Tau Hyperphosphorylation. Evid. Based Complement. Alternat. Med. 2017 (20), 5934254. doi: 10.1155/2017/5934254

Yang, Y., Li, Y., Li, S., Liu, X., and Wang, Q. (2018). Comparison of experimental maze tests used to assess the learning and memory abilities in rats and mice. Chin. J. Comp. Med. 28 (12), 129-134. doi: 10.3969/j.issn.16717856.2018.12.022

Yongliang, Z., Qiong, W., Hailong, C., Xinmin, L., Ke, L., Tingmei, W., et al. (2018). Involvement of cholinergic dysfunction and oxidative damage in the effects of simulated weightlessness on learning and memory in rats. BioMed. Res. Int. 2018 (1), 1-11. doi: 10.1155/2018/2547532

Yutaro, K., Hiroyuki, I., Chie, K., Kimiko, K., Hiroshi, T., Toshiyuki, M., et al. (2018). Oral administration of Pantoea agglomerans-derived lipopolysaccharide prevents metabolic dysfunction and Alzheimer's disease-related memory loss in senescence-accelerated prone 8 (SAMP8) mice fed a high-fat diet. PloS One 13 (6), e0198493. doi: 10.1371/ journal.pone. 0198493

Zhang, X. Y., Cao, J. B., Zhang, L. M., Li, Y. F., and Mi, W. D. (2015). Deferoxamine attenuates lipopolysaccharide-induced neuroinflammation and memory impairment in mice. J. Neuroinflamm. 12 (1), 20. doi: 10.1186/s12974-015-0238-3

Zhang, Y., Hu, W., Zhang, B., Yin, Y., Zhang, J., Huang, D., et al. (2017). Ginsenoside Rg1 protects against neuronal degeneration induced by chronic dexamethasone treatment by inhibiting NLRP-1 inflammasomes in mice. Int J. Mol. Med. 40 (4), 1134-1142. doi: 10.3892/ijmm.2017.3092

Zhang, J. (2000). Comparison of pharmacological effects of Ginsenoside Rg1 and Rb1. Basic Med. Sci. Clinics 20 (5), 4-6. doi: 1001-6325 2000 05-0004-03

Zhao, H. H., Di, J., Liu, W. S., Liu, H. L., Lai, H., and Lu, Y. L. (2013). Involvement of GSK3 and PP2A in ginsenoside Rb1"s attenuation of aluminum-induced tau hyperphosphorylation. Behav. Brain Res. 241, 228-234. doi: 10.1016/ j.bbr.2012.11.037

Conflict of Interest: The authors declare that the research was conducted in the absence of any commercial or financial relationships that could be construed as a potential conflict of interest.

Copyright $\odot 2020$ Yang, Li, Huang, Lv, Chen, Pires Dias, Li, Liu and Wang. This is an open-access article distributed under the terms of the Creative Commons Attribution License (CC BY). The use, distribution or reproduction in other forums is permitted, provided the original author(s) and the copyright owner(s) are credited and that the original publication in this journal is cited, in accordance with accepted academic practice. No use, distribution or reproduction is permitted which does not comply with these terms. 